\title{
Highly Luminescent Lanthanide Complexes of 1-Hydroxy-2-pyridinones
}

Evan G. Moore, Jide Xu, Christoph J. Jocher, Ingrid Castro-Rodriguez and Kenneth N. Raymond*

\author{
Department of Chemistry, University of California, Berkeley, CA, 94720-1460 \\ and \\ Lawrence Berkeley National Laboratory, Berkeley, CA 94720.
}

\section{Abstract}

The synthesis, X-ray structure, stability, and photophysical properties of several trivalent lanthanide complexes formed from two differing bis-bidentate ligands incorporating either alkyl or alkyl ether linkages and featuring the 1-hydroxy-2-pyridinone (1,2-HOPO) chelate group in complex with Eu(III), $\mathrm{Sm}(\mathrm{III})$ and $\mathrm{Gd}(\mathrm{III})$ are reported. The Eu(III) complexes are among some of the best examples, pairing highly efficient emission ( $\Phi_{\text {tot }}^{E u} \sim 21.5 \%$, ) with high stability (pEu 18.6) in aqueous solution, and are excellent candidates for use in biological assays. A comparison of the observed behavior of the complexes with differing backbone linkages shows remarkable similarities, both in stability and photophysical properties. Low temperature photophysical measurements for a Gd(III) complex were also used to gain insight into the electronic structure, and were found to agree with corresponding TD-DFT calculations for a model complex. A comparison of the high resolution Eu(III) emission spectra in solution and from single crystals also revealed a more symmetric coordination geometry about the metal ion in solution due to dynamic rotation of the observed solid state structure.

\section{Introduction}

The ability to detect analytes such as DNA ${ }^{1}$, proteins ${ }^{2}$ or other biologically active molecules ${ }^{3}$ at small concentrations and in the presence of a complicated matrix or even in vivo remains a challenging task. Many of these bioassays often rely on lanthanide fluorescence, which can furnish detection limits in the nano- and picomolar region. ${ }^{4}$ Specifically, their sharp 'atom-like' emission spectra, large Stokes shift, and long lived luminescence makes trivalent lanthanide cations such as Eu(III) very attractive reporters for these assays. Using both spectral and temporal discrimination of the luminescent signal from background autofluorescence enables highly sensitive assays, ${ }^{5,6}$ such as the Dissociation Enhanced Lanthanide Fluoro Immuno Assay $\left(\right.$ DELFIA $^{\circledR}$ ) techniques first commercialized by Wallac ${ }^{\text {TM }}$, which use a polyaminocarboxylate chelate of $\mathrm{Eu}(\mathrm{III}){ }^{7}{ }^{7}$ However, the DELFIA ${ }^{\circledR}$ format is heterogeneous and suffers from the limitation that the fluorescent signal cannot be traced until the end of the assay, when the non-fluorescent $\mathrm{Ln}$ (III) chelate is converted to a highly fluorescent form by the addition of a sensitizing -diketonate enhancement solution. Hence, the preparation of efficient lanthanide sensitizers which also form very stable complexes in dilute aqueous solution is an active area of research, since they can be utilized directly and/or covalently bound to a particular biomolecule for use in a less expensive and less time consuming homogenous assays formats.

Some earlier examples of systems utilized in this manner and which have been very successful were based on Eu(III) cryptates originally developed by Lehn. ${ }^{8}$ However, in these cases, optimum results often required the addition of an augmenting agent such as anionic fluoride to displace residual inner sphere water molecules, which otherwise strongly quench Eu(III) centered luminescence. ${ }^{9}$ More recently, several relatively stable Ln(III) complexes with a tetrapodal ligand design incorporating four picolinate chelating moieties have been prepared, which were found to be quite efficient sensitizers of $\mathrm{Tb}$ (III), with overall luminescence quantum yield of $\Phi_{\text {tot }}^{T b}=45 \%$ and, to a lesser extent, for $\mathrm{Eu}$ (III) 
$\left(\Phi_{\text {tot }}^{E u}=7.0 \%\right) .{ }^{10}$ Conditional stability constant $(\mathrm{pM})$ measurements ${ }^{11}$ showed that these water soluble complexes possessed solution stability that exceeds that of EDTA ( $\mathrm{pEu}=15.5)$. However, the observed excitation maximum was quite high in energy, with a $\lambda_{\max }$ at $274 \mathrm{~nm}$. For biological applications, it is preferably that such complexes allow for sensitization of the metal using the lowest possible energy (longer wavelength) in order to minimize autofluorescence and to increase the penetration depth of excitation into the sample. ${ }^{12}$ Another recently described Eu(III) chelate, which has the advantage of red shifted excitation at $335 \mathrm{~nm}$, was reported by Matsumoto et. al. ${ }^{13}$ This compound is a polycarboxylate derivative of a terpyridine complex, and, according to preliminary stability assessment by competition with EDTA, is several orders of magnitude more stable than the [Eu(EDTA)] complex at $\mathrm{pH} 8$. However, the synthesis of the complex is quite lengthy and the intensity of the resulting Eu(III) emission remains only moderate, with $\Phi_{\text {tot }}^{E u}=9.1 \%$.

Another approach pioneered by Parker has been the covalent attachment of a variety of sensitizing chromophores to the macrocyclic DO3A platform, most recently utilizing azaxanthones and azathioxanthones as the light absorbing chromophore which has extended the absorption envelope as far as ca. $380 \mathrm{~nm} .{ }^{14}$ While stability data were not reported, these DO3A macrocyclic based complexes are known to form stable and very kinetically inert complexes with $\operatorname{Ln}(\mathrm{III})$ cations, ${ }^{15}$ and they almost certainly possess sufficient stability for biological applications. Despite their long wavelength absorbance, these chromophores have a relatively small energy gap between their first excited singlet and the lowest energy sensitizing triplet state, which facilitated their use as sensitizer for both $\mathrm{Tb}$ (III) and $\mathrm{Eu}(\mathrm{III})$. However, their luminescence performance is limited by incomplete energy transfer to the metal (as evidenced by residual ligand centered emission) and, more importantly, the presence of a single water molecule in the first coordination sphere $(q=1)$. Nonetheless, the observed quantum yields with $\mathrm{Eu}(\mathrm{III})$ were still very good with $\Phi_{\text {tot }}^{E u}=8.9 \%$, and for $\mathrm{Tb}(\mathrm{III})$, improved values as high as $\Phi_{\text {tot }}^{T b}=24 \%$ were reported, remarkably high for a $q=1$ complex.

The sensitization of trivalent lanthanides with the simple 1-hydroxy-2-pyridinone (1,2-HOPO) chromophore has been previously reported, ${ }^{16,17}$ specifically focusing on the $\left[\mathrm{ML}_{3}\left(\mathrm{H}_{2} \mathrm{O}\right)_{2}\right]$ or $\left[\mathrm{ML}_{4}\right]^{-}$ complexes with $\mathrm{Tb}(\mathrm{III}), \mathrm{Dy}(\mathrm{III})$ and $\mathrm{Eu}(\mathrm{III})$, which were also characterized by X-ray crystallography. In those studies the focus was on $\mathrm{Tb}(\mathrm{III})$, which displayed an impressive quantum yield of $\Phi_{\text {tot }}^{T b}=20 \%$ in methanol solution, whereas the performance of the $\mathrm{Eu}(\mathrm{III})$ complex was much less striking with $\Phi_{t o t}^{E u}=0.3 \%$. Recently, we discovered that the 6- amide derivatives of 1,2-HOPO have vastly improved performance for $\mathrm{Eu}(\mathrm{III})$, and we have reported on their excellent sensitization efficiency. ${ }^{18}$ The tetradentate ligand, 5LIO-1,2-HOPO $\left(\mathrm{H}_{2} \mathbf{1}\right.$, Chart 1), is remarkable in that its $\mathrm{ML}_{2}$ complex with Eu(III) combines both a very high quantum yield $\left(\Phi_{\text {tot }}^{E u}=21.5 \%\right)$ with exceptionally good aqueous stability ( $\mathrm{pEu}=18.6)$. Indeed, a comparison of the stability data for $\mathrm{Fe}(\mathrm{III}), \mathrm{Al}(\mathrm{III})$, and $\mathrm{Ga}(\mathrm{III})$ complexes of 1,2-HOPO's indicates that this group acts as a very strong chelator for Lewis acidic trivalent ions such as $\operatorname{Ln}(\mathrm{III}),{ }^{19,}{ }^{20}$ while conversely forming significantly weaker complexes with divalent ions such as $\mathrm{Cu}$ (II) or $\mathrm{Zn}(\mathrm{II}) .^{21}$ Furthermore, another important advantage of using the 6-carboxy-1-hydroxy-2pyridinone precursor is the facile preparation of multidentate 1,2-HOPO based ligands which are able to exploit the chelate effect for higher complex stabilities. ${ }^{22}$ These ligands also allow a certain measure of control over the Ln(III) coordination sphere, by providing steric bulk and helping prevent the coordination of inner sphere solvent molecules, when compared to the bidentate analogues. In this paper we elaborate on our previous communication ${ }^{18}$ to include the alkyl linked ligand 5LI-1,2-HOPO $\left(\mathrm{H}_{2} 2\right.$, Chart 1), in complex with Eu(III) and, as a result of the now completed photophysical characterization of the chromophore, we broaden the scope to include the complexes of both ligands with Sm(III). 


\section{Experimental \\ General}

All solvents for reactions were dried using standard methodologies. Thin-layer chromotography (TLC) was performed using precoated Kieselgel 60 F254 plates. Flash chromatography was performed using EM Science Silica Gel 60 (230- 400 mesh). NMR spectra were obtained using either Bruker AM300 or DRX-500 spectrometers operating at $300(75) \mathrm{MHz}$ and $500(125) \mathrm{MHz}$ for ${ }^{1} \mathrm{H}$ (or ${ }^{13} \mathrm{C}$ ) respectively. ${ }^{1} \mathrm{H}$ (or ${ }^{13} \mathrm{C}$ ) chemical shifts are reported in ppm relative to the solvent resonances, taken as $\delta 7.26(\delta 77.0)$ and $\delta 2.49(\delta 39.5)$ respectively for $\mathrm{CDCl}_{3}$ and $\left(\mathrm{CD}_{3}\right)_{2} \mathrm{SO}$ while coupling constants $(J)$ are reported in Hz. The following standard abbreviations are used for characterization of ${ }^{1} \mathrm{H}$ NMR signals: $\mathrm{s}=$ singlet, $\mathrm{d}=$ doublet, $\mathrm{t}=$ triplet, $\mathrm{q}=$ quartet, quin $=$ quintet, $\mathrm{m}=$ multiplet, $\mathrm{dd}=$ doublet of doublets. Fast-atom bombardment mass spectra (FABMS) were performed using 3-nitrobenzyl alcohol (NBA) or thioglycerol/glycerol (TG/G) as the matrix. Elemental analyses were performed by the Microanalytical Laboratory, University of California, Berkeley, CA.

\section{Synthesis}

Detailed synthesis of several relevant precursors (see Scheme 1) including the thiazolide activated derivative 1,2-HOPO-Bn-thiaz (6) starting from commercially available 6-bromo-picolinic acid have been described elsewhere. ${ }^{23}$ Similarly, the synthesis of 5LIO-1,2-HOPO $\left(\mathrm{H}_{2} \mathbf{1}\right)$ and its' Eu(III) complex as the pyridinium salt, $\mathrm{C}_{5} \mathrm{H}_{6} \mathrm{~N}\left[\mathrm{Eu}(\mathbf{1})_{2}\right]$, have been previously reported. ${ }^{18} \mathrm{~A}$ detailed synthesis of 5LI-1,2-HOPO $\left(\mathrm{H}_{2} 2\right)$ and its $\mathrm{Eu}(\mathrm{III})$ complex, $\mathrm{C}_{5} \mathrm{H}_{6} \mathrm{~N}\left[\mathrm{Eu}(\mathbf{2})_{2}\right]$, is described below, and corresponding complexes of $\mathrm{Sm}(\mathrm{III})$ and $\mathrm{Gd}(\mathrm{III})$ were prepared using the same procedure.

\section{LI-1,2-HOPO-Bn (8)}

To a solution of 1,2-HOPO-Bn-thiaz (6) $(1.22 \mathrm{~g}, 3.52 \mathrm{mmol})$ in dry $\mathrm{CH}_{2} \mathrm{Cl}_{2}(30 \mathrm{~mL})$ was added neat 1,5-pentanediamine (184 mg, $1.8 \mathrm{mmol})$. The resulting mixture was left to stir overnight, and ensuing purification of the reaction mixture was realized by removal of the solvent at reduced pressure and subsequent loading of the residue onto a flash silica column. Gradient elution with 2-6\% $\mathrm{MeOH}$ in $\mathrm{CH}_{2} \mathrm{Cl}_{2}$ allowed separation of the benzyl-protected precursor, 5LI-1,2-HOPO-Bn, as a pale yellow oil $(0.9 \mathrm{~g}, 92 \%) .{ }^{1} \mathrm{H}$ NMR $\left(300 \mathrm{MHz}, \mathrm{CDCl}_{3}\right.$ ): $\delta 1.18$ (quin, $2 \mathrm{H}$ ), 1.39 (quin, 4H), 3.17 (q, 4H), 5.26 (s, $4 \mathrm{H}), 6.32(\mathrm{dd}, 2 \mathrm{H}), 6.62(\mathrm{dd}, 2 \mathrm{H}), 6.78(\mathrm{t}, 2 \mathrm{H}), 7.26-7.45(\mathrm{~m}, 12 \mathrm{H}) .{ }^{13} \mathrm{C}$ NMR $\left(75 \mathrm{MHz}, \mathrm{CDCl}_{3}\right)$ : $\delta 23.4,27.9,39.3,79.1,105.9,123.2,128.4,129.2,129.9133 .2,138.5,142.9,158.5,160.3$.

\section{LI-1,2-HOPO $\left(\mathrm{H}_{2} 2\right)$}

5LI-1,2-HOPO-Bn (8) $(557 \mathrm{mg}, 1.0 \mathrm{mmol})$ was dissolved in a conc. $\mathrm{HCl} /$ glacial AcOH mixture $(20 \mathrm{~mL}, 1: 1(\mathrm{v} / \mathrm{v}))$, and was stirred at room temperature for 2 days. Filtration followed by removal of the solvent yielded a beige residue, which was washed with $\mathrm{Et}_{2} \mathrm{O}$ to give 5LI-1,2-HOPO as a beige powder (344 mg, $74 \%$ ). ${ }^{1} \mathrm{H}$ NMR (300 MHz, $\left(\mathrm{CD}_{3}\right)_{2} \mathrm{SO}$ ): $\delta 1.35$ (quin, $\left.2 \mathrm{H}\right), 1.46$ (quin, 4H), 3.18 (q, $4 \mathrm{H}), 6.26(\mathrm{dd}, 2 \mathrm{H}), 6.55(\mathrm{dd}, 2 \mathrm{H}), 7.37(\mathrm{dd}, 2 \mathrm{H}), 8.73(\mathrm{t}, 2 \mathrm{H}) . \mathrm{MS}(\mathrm{FAB}+): 377\left(\mathrm{MH}^{+}\right)$. Elemental Analysis for $\mathrm{C}_{17} \mathrm{H}_{20} \mathrm{~N}_{4} \mathrm{O}_{6} \cdot 2 \mathrm{HCl} \cdot \mathrm{H}_{2} \mathrm{O}\left(\mathrm{M}_{\mathrm{r}}=467.30 \mathrm{~g} . \mathrm{mol}^{-1}\right)$, Calc'd. (Found): 43.69 (43.75), 5.17 (4.93), 11.98 (11.65).

\section{$\mathrm{C}_{5} \mathrm{H}_{6} \mathrm{~N}\left[\mathrm{Eu}(5 \mathrm{LI}-1,2-\mathrm{HOPO})_{2}\right]\left(\mathrm{C}_{5} \mathrm{H}_{6} \mathrm{~N}\left[\mathrm{Eu}(2)_{2}\right]\right)$}

A solution of $\mathrm{EuCl}_{3} \cdot 6 \mathrm{H}_{2} \mathrm{O}(37 \mathrm{mg}, 0.1 \mathrm{mmol})$ in $\mathrm{MeOH}(1 \mathrm{~mL})$ was added to a stirred solution of $\mathrm{H}_{2} 2(94 \mathrm{mg}, 0.20 \mathrm{mmol})$ in $\mathrm{MeOH}(5 \mathrm{~mL})$. The clear solution became turbid after 2 drops of dry pyridine was added. The mixture was heated to reflux for $6 \mathrm{hr}$ under nitrogen, during which time the complex deposited as a white precipitate. This solid was isolated by filtration, rinsed with cold $\mathrm{MeOH}$, and dried to give the pyridinium salt of complex $(80 \mathrm{mg}, 82 \%)$ as a white solid. Elemental Analysis for $\mathrm{EuC}_{34} \mathrm{H}_{36} \mathrm{~N}_{8} \mathrm{O}_{12} \cdot \mathrm{C}_{5} \mathrm{H}_{6} \mathrm{~N}\left(\mathrm{M}_{\mathrm{r}}=980.77\right.$ g.mol $\left.{ }^{-1}\right)$ ), Calc'd. (Found): C, 47.76 (47.45); H, 4.32 (4.22); $\mathrm{N}, 12.85$ (12.67). MS (ES-): $900.1\left(\mathrm{M}^{-}\right)$. Crystals of the complex suitable for X-ray diffraction studies were prepared by vapor diffusion of ether into a wet methanol solution of the complex in the presence of excess dimethylamine. 


\section{Physical Methods \\ Crystallography}

Crystals suitable for X-ray analysis were mounted on a Kapton loop using Paratone $\mathrm{N}$ hydrocarbon oil and measured at low temperature using a Siemens SMART CCD ${ }^{24}$ area detector with graphite monochromated Mo-K $\alpha$ radiation. Cell constants and orientation matrices were obtained from leastsquares refinement. The resulting data were integrated by the program SAINT $^{25}$ and corrected for Lorentz and polarization effects. Data were also analyzed for agreement and possible absorption using XPREP. ${ }^{26}$ An empirical absorption correction based on the comparison of redundant and equivalent reflections was applied using SADABS. ${ }^{27}$ Equivalent reflections where appropriate were merged and no decay correction was applied. The structures were solved within the WinGX ${ }^{28}$ package by direct methods using SIR92 ${ }^{29}$ and expanded using full-matrix least-squares techniques with SHELXL-97 ${ }^{30}$. Hydrogen atoms were positioned geometrically, with $\mathrm{C}-\mathrm{H}=0.93 \AA$ for $\mathrm{CH}$ aromatic, $\mathrm{C}-\mathrm{H}=0.97 \AA$ for $\mathrm{CH}_{2}$ methylene, $\mathrm{N}-\mathrm{H}=0.89 \AA$, and $\mathrm{C}-\mathrm{H}=0.96 \AA$ for $\mathrm{CH}_{3}$ methyl. Hydrogen atoms were constrained to ride on their parent atoms, with $\mathrm{U}_{\text {iso }}(\mathrm{H})$ values set at 1.2 times $\mathrm{U}_{\mathrm{eq}}(\mathrm{C})$ for all $\mathrm{H}$ atoms. Resulting drawings of molecules were produced with ORTEP-3. ${ }^{31}$

\section{Solution Thermodynamics}

Experimental protocols and details of the apparatus closely followed those of a previous study for related ligands. ${ }^{32}$ The 5LI-1,2-HOPO $\left(\mathrm{H}_{2} 2\right)$ ligand and corresponding $\left[\mathrm{Eu}(2)_{2}\right]^{-}$complex protonation constants were examined by potentiometric titrations ( $\mathrm{pH} v s$ total proton concentration) using Hyperquad $^{33}$. Spectrophotometric titrations (absorbance $v s \mathrm{pH}$ ) were examined using $\mathrm{pHab}^{34}$ for data analysis. Both methods result in identical $\mathrm{pK}_{\mathrm{a}}$ values within experimental error.

All experiments were performed at $25^{\circ} \mathrm{C}$ and with $0.1 \mathrm{M} \mathrm{KCl}$ as electrolyte. Each determination results from three independent experiments, where each experiment consists of two titrations, first against $0.1 \mathrm{M} \mathrm{HCl}$ followed by reverse titrations against $0.1 \mathrm{M} \mathrm{KOH}$. Additionally, protonation constants of the metal complex at low $\mathrm{pH}$ values were measured, where each experiment consists of one titration from $\mathrm{pH} 3$ to $\mathrm{pH}$ 1.6. A correction of the liquid-liquid junction potential was performed in the course of $\mathrm{pH}$ electrode calibration, as detailed elsewhere. ${ }^{35}$ Equilibration times for titrations were $150 \mathrm{~s}$ and $210 \mathrm{~s}$ for ligand only and metal complex titrations respectively. Ligand and metal concentrations were in the range of 0.1 to $0.5 \mathrm{mM}$ for potentiometric titrations. For spectrophotometric titrations, the ligand and metal complex concentrations were $c a$. $0.01 \mu \mathrm{M}$.

As a result of the strength of the binding interaction, and the highly acidic nature of the ligand, the $\mathrm{Eu}$ (III) $\mathrm{ML}_{2}$ complex formation constants with either ligand could not be determined directly. As such, for the determination of the $\mathrm{ML}_{2}$ formation constant, $\beta_{120}$, spectrophotometric titrations versus the known competitor, DTPA, were performed between $\mathrm{pH} 5$ and 9 with competitor concentration ranging from $0.01 \mu \mathrm{M}$ to $0.12 \mathrm{mM}$. Additional spectrophotometric titrations with differing concentrations of $\mathrm{Eu}(\mathrm{III})$ and ligand between $\mathrm{pH} 3$ and 1.6 in the absence of the DTPA competitor then allowed the determination of the constants $\beta_{121}$ and $\beta_{110}$ from refinements with fixed $\beta_{120}$.

\section{Photophysics}

UV-Visible absorption spectra were recorded on Cary 300 double beam absorption spectrometer using quartz cells of $1.0 \mathrm{~cm}$ path length. Emission spectra were acquired on a HORIBA Jobin Yvon IBH FluoroLog-3 spectrofluorimeter. Spectra were reference corrected for both the excitation light source variation (lamp and grating) and the emission spectral response (detector and grating). Quantum yields were determined by the optically dilute method ${ }^{36}$ using the following equation;

$$
\frac{\Phi_{x}}{\Phi_{r}}=\left[\frac{A_{r}\left(\lambda_{r}\right)}{A_{x}\left(\lambda_{x}\right)}\right]\left[\frac{I\left(\lambda_{r}\right)}{I\left(\lambda_{x}\right)}\right]\left[\frac{\eta_{x}^{2}}{\eta_{r}^{2}}\right]\left[\frac{D_{x}}{D_{r}}\right]
$$

where $A$ is the absorbance at the excitation wavelength $(\lambda), I$ is the intensity of the excitation light at the same wavelength, $\eta$ is the refractive index and $D$ is the integrated luminescence intensity. The 
subscripts ' $x$ ' and ' $r$ ' refer to the sample and reference respectively. Quinine sulfate in $1.0 \mathrm{~N}$ sulfuric acid was used as the reference $\left(\Phi_{r}=0.546\right){ }^{36}$

Luminescence lifetimes were determined with a HORIBA Jobin Yvon IBH FluoroLog-3 spectrofluorimeter, adapted for time resolved measurements. A sub-microsecond Xenon flash lamp (Jobin Yvon, 5000XeF) was used as the light source, coupled to a double grating excitation monochromator for spectral selection. The input pulse energy (100 nF discharge capacitance) was ca. $50 \mathrm{~mJ}$, yielding an optical pulse duration of less than $300 \mathrm{~ns}$ at FWHM. A thermoelectrically cooled single photon detection module (HORIBA Jobin Yvon IBH, TBX-04-D) incorporating fast rise time PMT, wide bandwidth pre-amplifier and picosecond constant fraction discriminator was used as the detector. Signals were acquired using an IBH DataStation Hub photon counting module and data analysis was performed using the commercially available DAS 6 decay analysis software package from HORIBA Jobin Yvon IBH. Goodness of fit was assessed by minimizing the reduced chi squared function, $\chi^{2}$, and a visual inspection of the weighted residuals. Each trace contained at least 10,000 points and the reported lifetime values result from at least three independent measurements.

Typical sample concentrations for absorption and fluorescence measurements were $c a .10^{-5}$ to $10^{-6} \mathrm{M}$ and $1.0 \mathrm{~cm}$ cells in quartz suprasil or equivalent were used. Solid state measurements performed for the $\mathrm{Eu}(\mathrm{III})$ complexes were accomplished by fixing a dispersion of crystalline material to a glass microscope slide with Krazy Glue ${ }^{\circledR}$ cyanoacrylate based adhesive. The luminescence spectra and lifetimes in this case were measured using front-face excitation at $22.5^{\circ}$.

\section{Computational Studies}

Ground state density functional theory (DFT) and time-dependent DFT (TD-DFT) calculations were performed at the Molecular Graphics and Computational Facility, College of Chemistry, University of California, Berkeley. In both cases, the B3LYP/6-311G++ (d,p) basis set provided in Gaussian'03 was used, with simplified input structures derived from a previously reported ${ }^{18}$ crystal structure. All calculations were done in the gas phase and geometry optimizations were performed with no symmetry restraints.

\section{Results and Discussion}

\section{Synthesis and Structure}

The first reported synthesis of a 6- amide functionalized 1-hydroxy-2-pyridinone (1,2-HOPO) chelate group appeared more than 20 years ago, ${ }^{37}$ wherein the 1-hydroxy-2-pyridinone-6-carboxylic acid (3, Scheme 1) was first activated with phosgene gas, then coupled with an amine backbone to provide an amide linked multidentate 1,2-HOPO ligand scaffold. However, this procedure is somewhat unattractive since phosgene is highly toxic and, moreover, the yields of these coupling reactions were quite low (ca.15-30\%). Additionally, the separation and purification of the final products are sometimes difficult, in most cases requiring purification by HPLC which limits the scale of the synthesis.

A more attractive approach toward the synthesis of 1,2-HOPO derivatives has since been developed, ${ }^{18,23}$ as illustrated in Scheme 1 for the 5LIO-1,2-HOPO $\left(\mathrm{H}_{2} \mathbf{1}\right)$ and 5LI-1,2-HOPO $\left(\mathrm{H}_{2} 2\right)$ ligands. This procedure relies on the inherently greater acidity of the $\mathrm{N}$-hydroxyl group, when compared to the carboxylic acid, which allows for near quantitative and selective benzyl protection. Upon treatment with oxalyl chloride, the benzyl protected 1,2-HOPO acid (4) can be easily converted to a 1,2HOPO acid chloride (5), which reacts with primary or secondary amines to afford amide linked benzyl protected products.

The intermediate 1,2-HOPO acid chloride (5) is a very reactive species, and should be used immediately after preparation in most cases. Alternately, the benzyl protected 1,2-HOPO acid can also be activated toward subsequent amide bond formation by various reagents such as NHS, HOBt or 2-mercaptothiazolide using DCC as the coupling agent and DMAP as a catalyst. The activated NHS ester, HOBT ester and thiazolide readily react with a large variety of backbone amines to form the desired benzyl-protected 1,2-HOPO intermediates $(\mathbf{7 , 8})$, which can be easily purified by flash 
chromatography on a preparative scale. As with the 1,2-HOPO acid chloride (5), the activated NHS and HOBT ester are not isolated in pure form, but rather generated and used in situ due to their reactivity. The 1,2-HOPO-Bn-thiaz (6) is therefore of particular interest since it can be easily separated and purified by flash chromatography and can also be stored since it is not sensitive to water and does not decompose. In most case, the 1,2-HOPO-Bn-thiaz (6) selectively reacts with primary amines to afford the desired benzyl protected products in excellent yield and the loss of its characteristic yellow color can also be used as a visual indicator to determine the end point of the amide coupling reaction. The deprotection of the ligands proceeds smoothly under strongly acidic conditions to afford the desired products after removal of the solvent at reduced pressure in analytically pure form and in good yield.

$\mathrm{X}$-ray quality crystals of $\mathrm{H}_{2} \mathbf{1}$ were obtained via vapor diffusion of diethyl ether into a solution of the ligand in methanol. A view of the resulting structure is shown in Figure 1, and crystal data is summarized in Table 1. Perhaps the most striking feature of this structure is the unusual geometry adopted by the ligand, likely a result of both intra- and intermolecular hydrogen bonding and also to a lesser extent $\pi$ stacking between adjacent 1,2-HOPO rings (vide infra). Both of the individual 1,2HOPO rings (defined by $\mathrm{C}_{1}-\mathrm{C}_{5}$ and $\mathrm{N}_{1}$, and $\mathrm{C}_{12}-\mathrm{C}_{16}$ and $\mathrm{N}_{4}$ ) are planar, with very small root mean square (rms) values (0.0032 and 0.0168 respectively), and the adjacent amide groups (defined by $\mathrm{C}_{6}$, $\mathrm{O}_{3}, \mathrm{~N}_{2}$ and $\mathrm{C}_{11}, \mathrm{O}_{5}, \mathrm{~N}_{3}$ ) are similarly also planar. As with similar structures reported previously, ${ }^{38}$ these amide groups are not coplanar with the adjacent 1,2-HOPO ring system, instead lying almost orthogonal with dihedral angles of $c a .88 .8^{\circ}$ and $62.2^{\circ}$ respectively. The observed short $\mathrm{C}-\mathrm{O}$ bondlengths between the $\mathrm{C} 1-\mathrm{O} 2$ and $\mathrm{C} 16-\mathrm{O} 7$ atoms at $1.26 \AA$ and $1.27 \AA$ respectively indicate the ligand is predominately in the 'keto' form. Indeed, 1,2-HOPO based ligand systems have previously been referred to as 'cyclic hydroxamic acids' rather than as the tautomeric conjugated aromatic ring system, based on similarity of UV-visible spectra to simpler analogs which cannot undergo this keto-enol tautomerisation. ${ }^{39}$

An examination of the crystal packing for $\mathrm{H}_{2} \mathbf{1}$ reveals a secondary arrangement of two distinct ligands to form dimers, which are held together by the $\pi$ stacking of adjacent 1,2-HOPO ring systems at a separation of $c a .3 .4 \AA$ and a complex network of intra- and intermolecular hydrogen bonds. For example, the protons of the phenolic $\mathrm{O} 1$ and $\mathrm{O} 6$ atoms form complementary bifurcated intermolecular $\mathrm{H}$-bonding interactions with the keto $\mathrm{O} 7(\mathrm{O} 1-\mathrm{H} 1 \cdots \mathrm{O} 7=1.75 \AA)$ and neighboring phenolic $\mathrm{O} 6$ atom $(\mathrm{O} 1-\mathrm{H} 1 \cdots \mathrm{O} 6=2.46 \AA)$, and keto $\mathrm{O} 2(\mathrm{O} 6-\mathrm{H} 6 \cdots \mathrm{O} 2=1.57 \AA)$ and neighboring phenolic O1 atoms (O6$\mathrm{H} 6 \cdots \mathrm{O} 1=2.52 \AA$ ) respectively. An additional intermolecular interaction between the amide $\mathrm{N} 3$ proton and keto $\mathrm{O} 7$ atom $(\mathrm{N} 3-\mathrm{H} 3 \cdots \mathrm{O} 7=2.13 \AA$ ) was also noted. Lastly, the presence of a single co-crystallized solvent water molecule may also have had a significant influence on the observed ligand geometry, since this molecule makes a total of three intermolecular $\mathrm{H}$-bonding contacts $(\mathrm{N} 2-\mathrm{H} 2 \mathrm{~A} \cdots \mathrm{O} 1 \mathrm{~W}=2.11 \AA$, $\mathrm{O} 1 \mathrm{~W}-\mathrm{H} 1 \mathrm{~W} 1 \cdots \mathrm{O} 3=1.91 \AA, \mathrm{O} 1 \mathrm{~W}-\mathrm{H} 1 \mathrm{~W} 2 \cdots \mathrm{O} 7=2.12 \AA$,) which link adjacent dimer units.

The complexation of either the 5LIO-1,2-HOPO $\left(\mathrm{H}_{2} \mathbf{1}\right)$ or 5LI-1,2-HOPO $\left(\mathrm{H}_{2} 2\right)$ ligands with various $\mathrm{LnCl}_{3} \cdot 6 \mathrm{H}_{2} \mathrm{O}$ salts $(\mathrm{Ln}=\mathrm{Eu}, \mathrm{Sm}, \mathrm{Gd})$ has been readily achieved using the appropriate 1:2 metal:ligand stoichiometry in the presence of pyridine acting as a base, and using $\mathrm{MeOH}$ as the solvent. After a short reflux period of $c a$. 4-6 hours, the desired $\mathrm{ML}_{2}$ complexes can be isolated upon cooling by filtration as the pyridinium salts in excellent yield and in analytically pure form. As detailed in the preceding communication, ${ }^{18}$ dissolving the isolated pyridinium salts of these complexes in an organic solvent such as $\mathrm{MeOH}$ or DMF in the presence of a smaller monocationic species such as tetramethylammonium or dimethylammonium followed by vapor diffusion with diethyl ether facilitated ready isolation of X-ray quality crystals and we previously reported ${ }^{18}$ the structure of the $\mathrm{C}_{4} \mathrm{H}_{12} \mathrm{~N}^{+}\left[\mathrm{Eu}(\mathbf{1})_{2}\right]^{-}$complex. Herein, $\mathrm{X}$-ray quality crystals were also obtained for the following complexes; $\mathrm{C}_{4} \mathrm{H}_{12} \mathrm{~N}^{+}\left[\mathrm{Sm}(\mathbf{1})_{2}\right]^{-} \cdot \mathrm{CH}_{3} \mathrm{OH} \cdot \mathrm{H}_{2} \mathrm{O}$, $\mathrm{C}_{4} \mathrm{H}_{12} \mathrm{~N}^{+}\left[\mathrm{Gd}(\mathbf{1})_{2}\right]^{-}, \mathrm{C}_{2} \mathrm{H}_{8} \mathrm{~N}^{+}\left[\mathrm{Eu}(\mathbf{2})_{2}\right]^{-} \cdot(\mathrm{DMF})_{2}$, and $\mathrm{C}_{2} \mathrm{H}_{8} \mathrm{~N}^{+}\left[\operatorname{Sm}(\mathbf{2})_{2}\right]^{-} \cdot(\mathrm{DMF})_{1.5}$ where $\mathrm{C}_{4} \mathrm{H}_{12} \mathrm{~N}^{+}$and $\mathrm{C}_{2} \mathrm{H}_{8} \mathrm{~N}^{+}$are the tetramethylammonium or dimethylammonium cations respectively. For completeness, the crystal data for the previously reported and new complexes are both summarized in Table 1, and corresponding views of these complexes are shown in Figures 2-4.

The $\left[\mathrm{Eu}(\mathbf{2})_{2}\right]^{-}$complex anion is shown in Figure 2, where the striking similarity to the previously reported $\left[\operatorname{Eu}(\mathbf{1})_{2}\right]^{-}$structure is also clearly evident. Relevant bond lengths are also summarized in Table 2. For both these structures, the oxophilic Eu(III) cation is surrounded by a total of eight oxygen donors, four from each of the two bis-bidentate ligands, with average Eu-O bond lengths of $c a$. $2.40 \AA$. 
In both complexes, a commonly observed feature are the strong intramolecular hydrogen bonding interactions between the amide proton and the adjacent coordinated N-hydroxyl oxygen atoms, with an average distance of $1.93 \AA$ for $\left[\operatorname{Eu}(\mathbf{1})_{2}\right]^{-}$and $1.90 \AA$ for $\left[\operatorname{Eu}(\mathbf{2})_{2}\right]^{-}$. For the latter, only three of the four maximum possible interactions of this type were observed, as one of the amide groups in this complex lies twisted out of plane to the adjacent 1,2-HOPO ring systems (N6-C23-C22-N5 dihedral angle, $\theta=84^{\circ}$ ). Significantly, this seemingly large distortion seems to have had little effect on the overall morphology of the final structure. For the $\left[\operatorname{Eu}(\mathbf{1})_{2}\right]^{-}$structure, the central ether oxygen of each ligand backbone is also involved in an intramolecular hydrogen bonding interaction with the amide protons. Lastly, it is relevant to note the orientation of each of the tetradentate ligands with respect to the other is almost identical between the two complexes, as shown in Figure 2.

The corresponding crystal structures for the $\mathrm{ML}_{2}$ complexes of $\mathrm{H}_{2} \mathbf{1}$ and $\mathrm{H}_{2} 2$ with $\mathrm{Sm}(\mathrm{III})$ are shown in Figure 3 and relevant bond lengths are again summarized in Table 2. As was the case with Eu(III), each Sm(III) metal centre is overall eight coordinate in each of the complex anions, with four donor atoms provided per ligand. The average Sm-O bond lengths are essentially identical, at ca. $2.41 \AA$, which are slightly larger when compared to the corresponding Eu(III) complexes (as expected due to the familiar lanthanide contraction ${ }^{40}$ ). A closer analysis of Figure 3 reveals a major and very significant difference between the $\left[\operatorname{Sm}(\mathbf{1})_{2}\right]^{-}$and $\left[\operatorname{Sm}(2)_{2}\right]^{-}$structures. In the latter case, the orientation of each of the tetradentate ligands with respect to each other is essentially identical to that observed for both $\mathrm{Eu}(\mathrm{III})$ complexes (see Figure 2) whereas for $\left[\operatorname{Sm}(\mathbf{1})_{2}\right]^{-}$, the orientation of the two bis-bidentate ligands are quite different. Hence, for this complex, the two five atom linkages between each 1,2-HOPO chelate can be described as being located on the same 'face' of the complex (forming a $c a .-55^{\circ}$ dihedral angle, as viewed down an imaginary rotational axis including the metal center and lying perpendicular to the page as drawn in Figure 3). By contrast, for the other three complexes discussed thus far, the five atom linker between each 1,2-HOPO chelate are offset by $c a .120^{\circ}$ such that they lie almost on the opposite 'face' of the complex. As evidenced by the similarity in coordinate bondlengths, however, this striking difference in orientation of the ligand backbones has little influence over the final structure of the complex. Nonetheless, it does serve to illustrate that each bis-bidentate chelate group is free to rotate with respect to the other, and it is likely the complexes will display fluxional behavior in solution.

Lastly, a view of the structure obtained for the $\left[\mathrm{Gd}(\mathbf{1})_{2}\right]^{-}$complex anion is shown in Figure 4, and relevant bond lengths are summarized in Table 2. Unfortunately, the quality of the crystal obtained for this complex was quite low, resulting in relatively poor diffraction data compared to the other complexes, but nonetheless a tenable solution was obtained. In keeping with the expected lanthanide contraction, the smaller $\mathrm{Gd}(\mathrm{III})$ metal centre exhibits slightly shorter Gd-O bondlengths, averaging $2.32 \AA$. The hydrogen bonding pattern observed for the Eu(III) and Sm(III) complexes between amide $\mathrm{N}-\mathrm{H}$ protons adjacent to the 1,2-HOPO ring system and the coordinated hydroxyl oxygen atom are maintained for the Gd(III) complex, as are the intramolecular $\mathrm{H}$ bonds to the central ether oxygen of the ligand. Lastly, the orientation of each ligand backbone with respect to the other again mimics that seen in both the $\mathrm{Eu}(\mathrm{III})$ complexes and also the structure of $\left[\operatorname{Sm}(2)_{2}\right]^{-}$, where each of the five atom linkages are on opposite faces of the structure, offset by a torsional angle of $\mathrm{ca} .125^{\circ}$.

An important structural parameter which can also be obtained from the crystallographic data is the shape measure, $S M,{ }^{41,42}$ defined as:

$$
S M=\min \left[\sqrt{\frac{1}{m} \sum_{i=1}^{m}\left(\delta_{i}-\theta_{i}\right)^{2}}\right]
$$

This is a measure of the agreement in the variance of dihedral angles along all edges between the polyhedron derived from the crystal structure and the idealized cases. For the eight coordinate geometry, the three most common idealized coordination polyhedra are shown in Figure 5, and correspond to the bicapped trigonal prismatic $\left(\mathrm{C}_{2 v}\right)$, square antiprismatic $\left(\mathrm{D}_{4 d}\right)$ and trigonal dodecahedral $\left(\mathrm{D}_{2 d}\right)$ geometries. The lowest value of $S M$ for the three pairs represents the best fit to the closest idealized geometry, and resulting shape measure calculations for the five complexes studied herein are summarized in Table 3. It is readily apparent the closest match for most of the complexes was 
the bicapped trigonal prismatic $\left(\mathrm{C}_{2 v}\right)$ geometry, with all but the $\left[\operatorname{Sm}(\mathbf{1})_{2}\right]^{-}$complex displaying this as the closest corresponding ideal coordination polyhedron. Notably, it was for only this complex that the orientation of the five atom linkages between 1,2-HOPO chelate groups differed with respect to each other (vide supra), and this structural difference is also likely the cause of the differing shape measure result.

\section{Solution Thermodynamics}

The protonation constants of 5LI-1,2-HOPO $\left(\mathrm{H}_{2} 2\right)$ were determined by potentiometry, with resulting parameters as summarized in Table 4. These values were also confirmed by spectrophotometric titrations, and were subsequently used to determine the calculated molar absorbance of the neutral $\mathrm{H}_{2} 2$, anionic $\mathrm{H2}^{-}$, and dianionic $\mathbf{2}^{2-}$ forms of the ligand as shown in Figure 7 . These can be compared directly to those previously reported ${ }^{18}$ for 5LIO-1,2-HOPO $\left(\mathrm{H}_{2} \mathbf{1}\right)$. As anticipated, the differing five carbon atom linkage has only a slight effect on the acidities of the two ligands.

It has been shown elsewhere ${ }^{43}$ that the difference between $\mathrm{pK}_{\mathrm{a} 1}$ and $\mathrm{pK}_{\mathrm{a} 2}$ of a diprotic ligand can be used as a measure of the average separation between protonation sites. Applied to the current situation, the difference in $\mathrm{pK}_{\mathrm{a}}$ values is slightly lower for $\mathrm{H}_{2} 2$ at 1.13 compared to $\mathrm{H}_{2} \mathbf{1}$ at 1.60 as shown in Table 4. Since both the 5LI- and 5LIO- backbones span approximately the same distance when fully elongated, it is reasonable that the differing protonation behavior as expressed by the difference in $\mathrm{pK}_{\mathrm{a}}$ values can be attributed to the presence of the central ether oxygen atom of the latter, resulting in a closer intermolecular distance on average between protonation sites. This can be rationalized by the presence of an intervening hydrogen bonding network, as drawn in Chart 1, involving the amide protons and the central ether oxygen, which ensures the two $\mathrm{N}$-hydroxamate functional groups remain in close proximity, and may also preorganize the 5LIO-1,2-HOPO ligand for metal chelation. The presence of this hydrogen bonding network for $5 \mathrm{LIO}-1,2-\mathrm{HOPO}$ may also account for the slight difference in $\mathrm{pK}_{\mathrm{a}}$ 's observed between the two differing ligands.

From the sum of $\mathrm{pK}_{\mathrm{a}}$ values (equivalent to the overall ligand acidity), it can be anticipated that $\mathrm{H}_{2} \mathbf{2}$, as the more basic ligand, will form a more stable $\mathrm{ML}_{2}$ complex than $\mathrm{H}_{2} \mathbf{1}$. Unfortunately, the cumulative formation constants with $\mathrm{Eu}(\mathrm{III})$ could not be measured directly, since $\mathrm{Eu}(\mathrm{III})$ was not released at $\mathrm{pH}$ values as low as 1.6 under the experimental conditions utilized. Hence, competition titration experiments as described elsewhere ${ }^{18}$ using DTPA as a known competitor were required to experimentally determine $\beta_{120}$, and this number was then fixed in subsequent refinements of potentiometric low $\mathrm{pH}$ titration data to obtain $\beta_{110}$ and $\beta_{121}$, with the resulting parameters as summarized in Table 4 . While the $\beta_{120}$ (and $\mathrm{pEu}$ values) are quite similar, a close inspection of this data reveals the expected improvement in $\mathrm{ML}_{2}$ complex stability for the $\mathrm{H}_{2} 2$ ligand was not borne out experimentally, instead revealing the $\mathrm{H}_{2} \mathbf{1}$ ligand forms the more stable $\mathrm{ML}_{2}$ chelate, with $\mathrm{pEu}=18.65(10)$ for $\left[\mathrm{Eu}(\mathbf{1})_{2}\right]^{-}$versus $\mathrm{pEu}=18.35(5)$ for $\left[\mathrm{Eu}(\mathbf{2})_{2}\right]^{-}$. As a rationale for this apparent inconsistency in chelate strengths, again, a consideration of the hydrogen bonding network operant between the two 1,2-HOPO units, and hence the rigidity of the backbone is instructive.

In the present case, hydrogen bonding interactions between the amide protons and the ether oxygen were observed crystallographically and it can be assumed that these hydrogen bond interactions will persist in solution. The effect of these interactions would be to rigidify the ligand and hence confer a slightly improved chelate effect, therefore increasing the stability for the ensuing $\mathrm{H}_{2} \mathbf{1}$ based complexes. For the aminocarboxylate ligands EEDTA and PeDTA (Chart 2), conditional stability measurements yielded pM values of 15.73 and 8.07 respectively with $\mathrm{Gd}(\mathrm{III}) .{ }^{35,44}$ In this case, it was presumed that the ether oxygen atom of EEDTA is also coordinated to the metal ion, which would contribute $c a$. $1.6 \mathrm{log}$ units per oxygen atom coordinated. The remaining difference in stability of $c a .4 \log$ units was attributed to the effect of rigidifying the scaffold. In the present case, the less pronounced difference observed in $\mathrm{Eu}$ (III) complex stability between $\mathrm{H}_{2} \mathbf{1}$ or $\mathrm{H}_{2} 2$ is most likely due to a less optimal geometry for these intramolecular hydrogen bonding interactions.

Lastly, as further evidence of the $\left[\operatorname{Eu}(\mathbf{1})_{2}\right]^{-}$and $\left[\mathrm{Eu}(\mathbf{2})_{2}\right]^{-}$complex stabilities, a comparison with ethylenediaminetetraacetic acid (EDTA) can be made. EDTA is a common assay component used in 
biological samples (usually for the removal of $\mathrm{Fe}(\mathrm{III})$ or other interfering metal cations) which also forms relatively strong octadentate complexes with the oxophilic $\mathrm{Ln}(\mathrm{III})$ cation $(\mathrm{eg} . \mathrm{pEu}=15.48)$. It is worthy then to note that, under pM conditions, the present $\left[\mathrm{Eu}(\mathbf{1})_{2}\right]^{-}$or $\left[\mathrm{Eu}(\mathbf{2})_{2}\right]^{-}$complexes can tolerate as much as a 1000 fold excess of EDTA relative to $\mathrm{Eu}(\mathrm{III})$, even though they are only tetradentate ligands, with no significant impact on the speciation and consequent luminescence intensity $(<7 \%$ decrease) as demonstrated in Figure 6.

\section{Photophysics}

The absorption spectra of the ligand $\mathrm{H}_{2} 2$ in its various protonation states are shown in Figure 7 , together with that of the $\left[\mathrm{Eu}(\mathbf{2})_{2}\right]^{-}$complex. Notably, the absorption spectrum of $\mathrm{H}_{2} \mathbf{2}$ is essentially identical to that reported previously for $\mathrm{H}_{2} 1{ }^{18}$ Specifically, either ligand with the 5LI- or 5LIObackbones yield a broad electronic envelope in the near UV assigned to a transition with mixed $n \rightarrow \pi^{*}$, $\pi \rightarrow \pi^{*}$ parentage (vide infra) with an apparent maxima at ca. $305 \mathrm{~nm}\left(\varepsilon \sim 12,400 \mathrm{M}^{-1} \mathrm{~cm}^{-1}\right)$. Upon deprotonation of either ligand to form the dianionic species, this band shifts to $\mathrm{ca} .345 \mathrm{~nm}$ and is reduced slightly in intensity $\left(\varepsilon \sim 8,900 \mathrm{M}^{-1} \mathrm{~cm}^{-1}\right)$.

Corresponding electronic structure calculations using TD-DFT were also performed using Gaussian' $03^{45}$ in order to further characterize the excited state of the 1,2-HOPO chromophore. As a simplified model, only the 6- methyl amide of 1,2-HOPO was used as the input structure, and this was first geometry optimized with no symmetry constraints to give the relaxed output geometry shown in Figure 8 . The output geometry obtained is reasonable, with all non- $\mathrm{H}$ atoms lying essentially in a single plane. The calculated structure also reproduced the expected strong $\mathrm{H}$ bonding interactions between the $\mathrm{N}$-hydroxyl proton and adjacent keto oxygen $(\mathrm{O} 1-\mathrm{H} \cdots \mathrm{O} 2=1.79 \AA)$ and similarly, between the amide proton and the N-hydroxyl oxygen atom $(\mathrm{N} 2-\mathrm{H} \cdots \mathrm{O} 1=1.89 \AA)$.

A summary of the electronic structure calculation is given in Table 5 and consideration of these results revealed the nature of the first excited singlet state of the 1,2-HOPO chromophore can be described principally by a HOMO $\rightarrow$ LUMO excitation, with a smaller contribution from the HOMO-4 $\rightarrow$ LUMO+1 excitation. Inspection of the relevant Kohn-Sham molecular orbitals also shown in Figure 8 reveal these transitions to be mixed $\pi-\pi^{*}$ and $n-\pi^{*}$ respectively. Similarly, the nature of the of the lowest triplet state $\left(\mathrm{T}_{0}\right)$ can be described principally by a HOMO $\rightarrow$ LUMO excitation, i.e. a ${ }^{3} \pi \pi^{*}$ transition.

The absorption spectrum of $\left[\operatorname{Eu}(\mathbf{2})_{2}\right]^{-}$is also shown in Figure 7, and is again almost identical to that previously observed $^{18}$ for $\left[\mathrm{Eu}(\mathbf{1})_{2}\right]^{-}$(Table 6). Specifically, the $\mathrm{ML}_{2}$ complexes for either (1) or (2) with both $\mathrm{Eu}(\mathrm{III})$ or $\mathrm{Sm}(\mathrm{III})$ gave essentially identical absorption profiles, with an apparent maxim at ca. $330 \mathrm{~nm}\left(\varepsilon_{\max }=9,200 \mathrm{M}^{-1} \mathrm{~cm}^{-1}\right)$ assigned to a transition with mixed $n \rightarrow \pi^{*}$ and $\pi \rightarrow \pi^{*}$ parentage.

A second TD-DFT calculation was also performed using Gaussian' $03^{45}$ in order to further characterize the excited state of the anionic 1,2-HOPO chromophore in complex with a metal cation. However, rather than performing computationally expensive calculations involving a trivalent lanthanide, we have adopted an approach analogous to that reported ${ }^{46}$ previously by Picard et. al., in this case replacing the $\mathrm{N}$-hydroxyl proton with a monovalent $\mathrm{Na}^{+}$cation, and adopting a bidentate chelating mode for the oxygen atoms in order to mirror the binding mode of a trivalent $\mathrm{Ln}(\mathrm{III})$ cation. While this is undoubtedly a crude model, we have found this approach to be quite useful as a tool for understanding the electronic structure. It must also be stressed that the goal of this 'calculation' is not to determine the electronic states of the $\mathrm{Ln}$ (III) cation, but rather to approximate the energy for the lowest excited singlet and triplet states of the ligand.

The resulting output geometry shown in Figure 9 where it is evident that all non- $\mathrm{H}$ atoms are essentially lying in a plane, and also the $\mathrm{Na}^{+}$cation has retained its bidentate coordination mode upon energy minimization. Bond lengths obtained between the sodium and $\mathrm{O} 1$ and $\mathrm{O} 2$ respectively were $2.16 \AA$ and $2.14 \AA$ respectively, slightly smaller than those observed with $\mathrm{Eu}$ (III) by $\mathrm{X}$-ray crystallography. Nonetheless, the geometries are very similar and a common feature of both the $\mathrm{Na}^{+}$ model and the Eu(III) X-ray structures is the conserved intramolecular H-bonding interaction between the amide proton and N-hydroxyl oxygen atom. 
The resulting electronic structure calculation is again summarized in Table 5 and relevant Kohn-Sham molecular orbitals are shown in Figure 9. Hence, the nature of the lowest energy triplet excited state for the $\mathrm{Na}^{+}$complex of an anionic 1,2-HOPO chromophore can be described principally by a HOMO $\rightarrow$ LUMO excitation, as was the case for the free ligand, with ${ }^{3} \pi \pi^{*}$ character. Significantly, an inspection of the orbitals involved in the lowest energy singlet transition (from HOMO $\rightarrow$ LUMO) demonstrates obvious ${ }^{1}$ LMCT character. However, the ca. $3.2 \mathrm{eV}$ energy calculated for this transition did not match any experimentally observed absorption at $c a .380 \mathrm{~nm}$, for either of the ligands (1) or (2) deprotonated with $\mathrm{NaOH}$, or indeed the absorption spectrum observed for the $\mathrm{Eu}(\mathrm{III})$ complexes. It has been noted ${ }^{47}$ that TD-DFT calculations using simple exchange correlational (xc) functionals such as the B3LYP/6-311G++ (d,p) basis set used here can yield substantial errors when estimating the excitation energy of charge transfer (CT) type transitions, due to self-interaction errors within the orbital energies of the ground-state DFT calculation. We conclude that it is likely this calculated transition is an artifact, and the ${ }^{1} \mathrm{LMCT}$ likely lies at much higher energy. A corresponding configuration interaction singles (CIS) calculation which is not subject to the same self-interaction error was also performed using the identical input geometry, and the resulting value estimated for the same HOMO-LUMO transition was located at significantly higher energy (ca. $4.89 \mathrm{eV}, 253.4 \mathrm{~nm}$ ). For the local valence excited states, the results from TD-DFT will be more reliable. Indeed, the estimated $S_{0} \rightarrow S_{2}$ transition calculated using this technique at $3.755 \mathrm{eV}$ can be described principally by a HOMO $\rightarrow$ LUMO+1 excitation, for which both Kohn-Sham orbitals are ligand centered (LC) and this transition can be readily assigned $\pi \rightarrow \pi^{*}$ character. The calculated position of this absorption at $c a .330 \mathrm{~nm}$ is in excellent agreement with those observed for both the Eu(III) and Sm(III) complexes of (1) and (2).

The normalized emission spectra for the $\left[\operatorname{Eu}(\mathbf{2})_{2}\right]^{-}$and $\left[\operatorname{Sm}(\mathbf{2})_{2}\right]^{-}$complexes are shown in Figure 10, and relevant photophysical data are summarized in Table 6. The emission spectrum of the Eu(III) complex is characteristic of the metal, with well resolved transitions from the metal centered ${ }^{5} \mathrm{D}_{0}$ excited state to ${ }^{7} \mathrm{~F}_{J}$ ground state multiplet readily apparent. Maximum intensities at 593, 612, 652 and $702 \mathrm{~nm}$ respectively were observed for the $\mathrm{J}=1,2,3$, and 4 transitions and, as was the case for the $\left[\mathrm{Eu}(\mathbf{1})_{2}\right]^{-}$ complex, the $J=2$ so-called 'hypersensitive' transition is extremely intense for both the pure alkyl and alkyl-ether linked backbones. The resulting luminescence quantum yields for the $\left[\mathrm{Eu}(2)_{2}\right]^{-}$complex in $0.1 \mathrm{M}$ TRIS buffer at $\mathrm{pH} 7.4$ were determined (relative to quinine sulfate in $1.0 \mathrm{~N} \mathrm{H}_{2} \mathrm{SO}_{4}, \Phi_{\text {ref }}=0.546$ ) and are comparable with those obtained ${ }^{18}$ for $\left[\mathrm{Eu}(\mathbf{1})_{2}\right]^{-}$. Evidently, slight structural modification of the tetradentate ligand involving replacement of the ether oxygen in the latter with a methylene group in $\left[\mathrm{Eu}(2)_{2}\right]^{-}$has little influence over the resulting photophysical behavior, with resulting $\Phi_{\text {tot }}$ values essentially identical within experimental error. This is further corroborated by the similarity in radiative $\left(k_{\mathrm{r}}\right)$ and non-radiative $\left(k_{\mathrm{nr}}\right)$ decay rate constants calculated using the method of Werts et. al. ${ }^{48}$ by comparing the integrated intensities of the $J=1$ transition to the total integrated area of the corrected emission spectrum (Table 6).

Corresponding time-resolved photophysical decay parameters for both complexes are also summarized in Table 6, using both $\mathrm{H}_{2} \mathrm{O}$ and $\mathrm{D}_{2} \mathrm{O}$ as solvent, which allowed the hydration number, ' $q$ ' to be determined, according to a recently reported ${ }^{49}$ improvement of the Horrock's equation;

$$
q=A^{\prime}\left(k_{\mathrm{H}}-k_{\mathrm{D}}-B\right)
$$

where $A^{\prime}$ and $B$ are empirical constants of 1.11 and $0.31 \mathrm{~ms}^{-1}$ for $\mathrm{Eu}(\mathrm{III})$ and $k_{\mathrm{D}}$ and $k_{\mathrm{H}}$ represent the observed luminescence decay rate constants, $k_{\mathrm{obs}}$, in deuterated and non-deuterated solvent respectively. The resulting values for ' $q$ ' were both essentially zero $\left(0.09 \pm 0.1\left[\operatorname{Eu}(\mathbf{1})_{2}\right]^{-}\right.$and $0.05 \pm 0.1$ for $\left.\left[\operatorname{Eu}(\mathbf{2})_{2}\right]^{-}\right)$ in accordance with the anticipated eight coordinate geometry and in agreement with the Eu(III) structures observed by crystallography.

Given the availability of crystalline X-ray quality samples for $\left[\operatorname{Eu}(\mathbf{1})_{2}\right]^{-}$and $\left[\operatorname{Eu}(\mathbf{2})_{2}\right]^{-}$, we were also able to perform solid state luminescence studies of the complexes, for which the coordination geometry is well characterized. Firstly, the metal centered luminescence lifetimes obtained for both $\left[\operatorname{Eu}(\mathbf{1})_{2}\right]^{-}$and $\left[\mathrm{Eu}(\mathbf{2})_{2}\right]^{-}$were consistently shorter than the corresponding solution measurements $(\mathrm{ca} .630 \mu \mathrm{sec} c f .730$ 
$\mu$ sec in $\mathrm{H}_{2} \mathrm{O}$ ), which may be attributed to a self-quenching mechanism operant in the closely packed solid $(\mathrm{Eu} \cdots \mathrm{Eu} \sim c a .9 \AA)$ as seen elsewhere for other $\mathrm{Ln}(\mathrm{III})$ systems. ${ }^{50}$ Of considerable more interest, however, was a closer inspection of the solid state compared with solution spectra in the region of the ${ }^{5} \mathrm{D}_{0} \rightarrow{ }^{7} \mathrm{~F}_{0,1}$ and ${ }^{5} \mathrm{D}_{0} \rightarrow{ }^{7} \mathrm{~F}_{2}$ transitions from $575-600 \mathrm{~nm}$ and $600-640 \mathrm{~nm}$ respectively.

Importantly, for both complexes, a single ${ }^{5} \mathrm{D}_{0} \rightarrow{ }^{7} \mathrm{~F}_{0}$ transition is observed, indicative of a single emitting species present in solution, and enabling site symmetry determination. ${ }^{51}$ For the ${ }^{5} \mathrm{D}_{0} \rightarrow{ }^{7} \mathrm{~F}_{1}$ transition, crystal field splitting of the $J=1$ level results in a maximum of three $(2 J+1)$ peaks in a low symmetry environment $\left(e g . \mathrm{C}_{2 v}\right)$ versus only two peaks for the hexagonal, trigonal or tetragonal point groups $\left(e g . \mathrm{D}_{2 d}, \mathrm{D}_{4 d}\right)$. The expected transitions derived from their principal character (either magnetic or electrical dipole) are shown in Table 7 for the three most common eight coordinate Ln(III) geometries that were shown previously in Figure 5.

As shown in the inset of Figure 10, three peaks are clearly evident in the ${ }^{5} \mathrm{D}_{0} \rightarrow{ }^{7} \mathrm{~F}_{1}$ region of the luminescence spectrum for a microcrystalline sample of $\left[\mathrm{Eu}(2)_{2}\right]^{-}$, with maxima at $587.7,591.6$ and $594.1 \mathrm{~nm}$. While the limited resolution $(\mathrm{ca} .0 .3 \mathrm{~nm})$ of the fluorescence spectrometer precludes a definitive determination of the exact point group of the complex, the data in Table 7 show that for the three most common coordination polyhedra, the best match to the observed luminescence spectra is obtained for the bicapped trigonal prism $\left(\mathrm{C}_{2 v}\right)$ geometry. It is certainly notable that this result agrees with the structure from X-ray crystallography, which shape analysis showed to be closest to $\mathrm{C}_{2 v}$ geometry.

By contrast, the corresponding emission spectrum from aqueous solution of $\left[\mathrm{Eu}(2)_{2}\right]^{-}$gave only two discernable peaks at 587.7 and $593.5 \mathrm{~nm}$, behavior indicative of a solution structure with higher symmetry than that observed in the solid state. Again, the data in Table 7 imply $\mathrm{D}_{4 d}$ or $\mathrm{D}_{2 d}$ symmetries, and further analysis of the band shape for the $J=2$ band at $c a .610 \mathrm{~nm}$ shows a distinct splitting of this band into two components (a smaller shoulder evident to lower energy), suggesting $\mathrm{D}_{2 d}$ symmetry as the closest match between the three idealized coordination polyhedra. Returning to the results from shape analysis for the $\left[\operatorname{Sm}(\mathbf{1})_{2}\right]^{-}$complex, it was noted that this complex had the closest match to $\mathrm{D}_{2 d}$ site symmetry, and in this case the ligand scaffolds were located on the same 'face' of the complex. As such, we may tentatively correlate this change in symmetry upon dissolution to the presence of an ensemble of emitting species, most with predominantly $\mathrm{D}_{2 d}$ symmetry. This differing symmetry when compared to the solid state structure can be realized in solution by free rotation of one ligand with respect to the other (about the central metal ion), although, given the millisecond lifetime of the Eu(III) luminescence, it is not possible to determine whether this change in symmetry occurs prior to or subsequent to formation of the excited state.

Metal centered luminescence was also seen as a faint pink emission upon UV irradiation from the Sm(III) complexes of (1) and (2), with several apparent maxima evident at ca. 563, 599, 646, and $710 \mathrm{~nm}$ corresponding to transitions from the ${ }^{4} \mathrm{G}_{5 / 2}$ excited state to lower ${ }^{6} \mathrm{~F}_{\mathrm{J}}$ and ${ }^{6} \mathrm{H}_{\mathrm{J}}$ levels. As shown in Figure 10, the most intense of these was the ${ }^{4} \mathrm{~F}_{9 / 2} \rightarrow{ }^{6} \mathrm{H}_{9 / 2}$ apparent at ca. $646 \mathrm{~nm}$. As was the case for the $\mathrm{Eu}(\mathrm{III})$ complexes, the spectra of either complex with (1) or (2) are essentially identical and the corresponding luminescence quantum yields and lifetimes are also summarized in Table 6. Notably, the $\mathrm{Sm}$ (III) spectra are less amenable to structural interpretation due to increased degeneracy of the states involved compared with $\mathrm{Eu}(\mathrm{III})$, and hence the corresponding solid state experiments were not performed.

The potential for $\mathrm{ML}_{2}$ complexes of (1) and (2) to sensitize other visible emitting lanthanide cations, notably Dy(III) and Tb(III), was also evaluated, however, metal centered luminescence was only noted for the Eu(III) and Sm(III) complexes. This behavior can be rationalized by a comparison and analysis of the room temperature and low temperature $(77 \mathrm{~K})$ phosphorescence spectra for the $\left[\mathrm{Gd}(\mathbf{1})_{2}\right]^{-}$complex (which lacks a low energy metal centered acceptor level) in a 1:1 EtOH:MeOH (v/v) glassing solvent, shown in Figure 11. At room temperature, relative ligand centered emission from the Gd(III) complex is very weak, with a faint signal attributed to singlet emission from the ligand apparent at ca. $400 \mathrm{~nm}$. However, upon cooling to $77 \mathrm{~K}$, this singlet emission is enhanced and a much more intense band appears from $450-600 \mathrm{~nm}$, which can be attributed to phosphorescence from the ligand $\mathrm{T}_{0}$ state. While 
this band displayed a poorly resolved vibronic progression, the $v_{00}$ electronic origin could not be unambiguously assigned. Rather, the lowest $\mathrm{T}_{0}$ energy was estimated by spectral deconvolution of the $77 \mathrm{~K}$ luminescence signal into several overlapping Gaussian functions to approximate an unresolved vibrational progression of $c a .1000-1100 \mathrm{~cm}^{-1}$. The resulting $\mathrm{T}_{0}$ energy was evaluated to be $c a$. $21,260 \mathrm{~cm}^{-1}$, which is remarkably similar to the value estimated using TD-DFT methods for the [Na(6-MeAmide-1,2-HOPO)] complex of $21,365 \mathrm{~cm}^{-1}$.

From the experimentally observed triplet energy, the sensitizing properties of the 1,2-HOPO chromophore can be readily understood in terms of the so-called energy gap law, ${ }^{52,53}$ since the energy of this level is located $c a .2230 \mathrm{~cm}^{-1}$ and $3980 \mathrm{~cm}^{-1}$ higher in energy than the potential ${ }^{5} \mathrm{D}_{1}$ and ${ }^{5} \mathrm{D}_{0}$ accepting levels in $\mathrm{Eu}(\mathrm{III})$, which facilitates efficient energy transfer. Similarly, for Sm(III), the $\mathrm{T}_{0}$ energy of the ligand is $c a .3360 \mathrm{~cm}^{-1}, 2360 \mathrm{~cm}^{-1}$ and $1210 \mathrm{~cm}^{-1}$ higher than the corresponding ${ }^{4} \mathrm{G}_{5 / 2}$, ${ }^{4} \mathrm{~F}_{3 / 2}$, and ${ }^{4} \mathrm{G}_{7 / 2}$ levels. By contrast, the lowest energy $\mathrm{Tb}(\mathrm{III})$ and $\mathrm{Dy}(\mathrm{III})$ acceptor levels are at $20,400 \mathrm{~cm}^{-1}\left({ }^{5} \mathrm{D}_{4}\right)$ and $21,100 \mathrm{~cm}^{-1}\left({ }^{4} \mathrm{~F}_{9 / 2}\right)$, both of which are only slightly lower in energy than the $\mathrm{T}_{0}$ state, and much less than the $c a .2500 \mathrm{~cm}^{-1}$ energy gap necessary to promote efficient sensitization of these metal centres. 52,53

\section{Conclusions}

The 1-hydroxy-2-pyridinone chelate group has proven to be a remarkably efficient sensitizer for $\mathrm{Eu}(\mathrm{III})$, which also forms extremely stable complexes in aqueous solution. The resistance to decomplexation of compounds of the type described herein, despite the presence of strong competitors such as EDTA, will be essential for their practical usage in bioanalytical applications. Furthermore, this chelate group can now be readily accessed, and the synthetic intermediates outlined herein allow for ease of systematic variations in the backbone connecting bis-bidentate ligands, and also allow for the preparation of more complex hexa- and octadentate derivatives.

A thorough investigation of the photophysical properties for these $\mathrm{Eu}(\mathrm{III})$ 1,2-HOPO complexes, including the location of the lowest energy triplet state, prompted our investigation with Sm(III) and has elucidated a more complete understanding of the sensitization process in terms of the energy gap between the excited singlet and triplet levels. Similarly, the results gained from TD-DFT calculations were advantageous in deciphering the electronic structure, and agreed well with the experimental data, despite the obvious simplicity of the model. Indeed, these results may prove useful as a predictive tool to guide synthetic efforts, at least in as far as ligand centered transitions can be predicted with a high level of accuracy.

\section{Acknowledgements}

This work was partially supported by the NIH (Grant HL69832) and supported by the Director, Office of Science, Office of Basic Energy Sciences, and the Division of Chemical Sciences, Geosciences, and Biosciences of the U.S. Department of Energy at LBNL under Contract No. DE-AC02-05CH11231. This technology is licensed to Lumiphore, Inc. in which some of the authors have a financial interest. Financial support was provided to C.J.J. by the German Research Foundation (DFG). The authors thank Dr. Kathleen Durkin and Ms. Amanda Samuel for assistance with the TD-DFT calculations.

\section{Supporting Information Available.}

X-ray crystallographic files (in CIF format) and Gaussian'03 output from TD-DFT and CIS calculations (in ASCII format). This material is available free of charge via the Internet at http://pubs.acs.org.

\section{References}

1. Vitzthum, F.; Bernhagen, J., Rec. Res. Dev. Anal. Biochem. 2002, 2, 65-93. 
2. $\quad$ Leca-Bouvier, B.; Blum, L. J., Anal. Lett. 2005, 38, 1491-1517.

3. Kimura, H.; Matsumoto, K.; Mukaida, M., J. Anal. Toxicol. 2005, 29, 799-805.

4. Jones, S. G.; Lee, D. Y.; Wright, J. F.; Jones, C. N.; Teear, M. L.; Gregory, S. J.; Burns, D. D., J. Fluorescence 2001, 11, 13-21.

5. $\quad$ Handl, H. L.; Gillies, R. J., Life Sci. 2005, 77, 361-371.

6. Petoud, S.; Cohen, S. M.; Bünzli, J.-C. G.; Raymond, K. N., J. Amer. Chem. Soc. 2003, 125, 13324-13325.

7. Hemmila, I.; Dakubu, S.; Mukkala, V. M.; Siitari, H.; Lovgren, T., Anal. Biochem. 1984, 137, 335-43.

8. Alpha, B.; Balzani, V.; Lehn, J. M.; Perathoner, S.; Sabbatini, N., Angew. Chem. 1987, 99, 131011.

9. Mathis, G., Clin. Chem. 1993, 39, 1953-9.

10. Chatterton, N.; Bretonniere, Y.; Pecaut, J.; Mazzanti, M., Angew. Chem. Int. Ed. 2005, 44, 75957598.

11. $\mathrm{pM}=-\log _{10}[\mathrm{M}]_{\text {free }}$. Defined as the negative log of the free metal $(\mathrm{M})$ concentration under $\mathrm{pH} 7.4$ conditions with $10 \mu \mathrm{M}[\mathrm{L}]_{\text {total }}$ and $1 \mu \mathrm{M}[\mathrm{M}]_{\text {total }}$.

12. Weissleder, R.; Ntziachristos, V., Nat. Med. 2003, 9, 123-8.

13. Nishioka, T.; Yuan, J.; Yamamoto, Y.; Sumitomo, K.; Wang, Z.; Hashino, K.; Hosoya, C.; Ikawa, K.; Wang, G.; Matsumoto, K., Inorg. Chem. 2006, 45, 4088-4096.

14. Atkinson, P.; Findlay, K. S.; Kielar, F.; Pal, R.; Parker, D.; Poole, R. A.; Puschmann, H.; Richardson, S. L.; Stenson, P. A.; Thompson, A. L.; Yu, J., Org. \& Biomol. Chem. 2006, 4, 1707-1722.

15. Kumar, K.; Chang, C. A.; Francesconi, L. C.; Dischino, D. D.; Malley, M. F.; Gougoutas, J. Z.; Tweedle, M. F., Inorg. Chem. 1994, 33, 3567-75.

16. Tedeschi, C.; Azema, J.; Gornitzka, H.; Tisnes, P.; Picard, C., Dalton Trans. 2003, 1738-1745.

17. Tedeschi, C.; Picard, C.; Azema, J.; Donnadieu, B.; Tisnes, P., New J. Chem. 2000, 24, 735-737.

18. Moore, E. G.; Xu, J.; Jocher, C. J.; Werner, E. J.; Raymond, K. N., J. Amer. Chem. Soc. 2006, 128, 10648-10649.

19. Clarke, E. T.; Martell, A. E.; Reibenspies, J., Inorg. Chim. Acta 1992, 196, 177-83.

20. Li, Y. J.; Martell, A. E., Inorg. Chim. Acta 1993, 214, 103-11.

21. Farkas, E.; Kozman, E.; Petho, M.; Herlihy, K. M.; Micera, G., Polyhedron 1998, 17, 33313342.

22. Moore, E. G.; Jocher, C. J.; Xu, J.; Werner, E. J.; Raymond, K. N., Inorg. Chem. 2007, 46, 54685470.

23. Xu, J.; Churchill, D. G.; Botta, M.; Raymond, K. N., Inorg. Chem. 2004, 43, 5492-5494.

24. SMART, Version 5.059: Area-Detector Software Package; Bruker Analytical X-ray Systems, Inc.: Madison, WI, 1999.

25. SAINT, Version 7.07B: SAX Area-Detector Integration Program; Siemens Industrial Automation, Inc.: Madison, WI, 2005.

26. XPREP, Version 6.12: Part of the SHELXTL Crystal Structure Determination Package; Bruker AXS Inc.: Madison, WI, 1995.

27. Sheldrick, G. SADABS, Version 2.10: Siemens Area Detector Absorption Correction Program; University of Göttingen: Göttingen, Germany, 2005.

28. WinGX 1.70.01: Farrugia, L. J. J. Appl. Crystallogr. 1999, 32, 837-838.

29. SIR92: Altomare, A.; Cascarano, G.; Giacovazzo, C.; Guagliardi, A. J. Appl. Crystallogr. 1993, 26, 343-350.

30. Sheldrick, G. M. SHELX97 - Programs for Crystal Structure Analysis; Institut fur Anorganische Chemie der Universitat:Gottingen, Germany, 1998.

31. ORTEP-3 for Windows: Farrugia, L. J. J. Appl. Crystallogr. 1997, 30, 565.

32. Johnson, A. R.; O'Sullivan, B.; Raymond, K. N., Inorg. Chem. 2000, 39, 2652-2660.

33. Gans, P.; Sabatini, A.; Vacca, A., Talanta 1996, 43, 1739-1753. 
34. Gans, P.; Sabatini, A.; Vacca, A., Annali di Chimica (Rome) 1999, 89, 45-49.

35. Martell, A. E.; Smith, R. M.; Editors, Critical Stability Constants, Vol. 1. 1974; p 263-270.

36. Crosby, G. A.; Demas, J. N., J. Phys. Chem. 1971, 75, 991-1024.

37. White, D. L.; Durbin, P. W.; Jeung, N.; Raymond, K. N., J. Med. Chem. 1988, 31, 11-8.

38. Scarrow, R. C.; Riley, P. E.; Abu-Dari, K.; White, D. L.; Raymond, K. N., Inorg. Chem. 1985, 24, 954-67.

39. Cunningham, K. G.; Newbold, G. T.; Spring, F. S.; Stark, J., J. Chem. Soc. 1949, 2091-4.

40. Seitz, M.; Oliver, A. G.; Raymond, K. N., J. Amer. Chem. Soc. 2007, 129, 11153-11160.

41. Porai-Koshits, M. A.; Aslanov, L. A., Zhurnal Strukturnoi Khimii 1972, 13, 266-76.

42. $\quad$ Kepert, D. L., Prog. Inorg. Chem. 1978, 24, 179-249.

43. Adams, E. Q., J. Amer. Chem. Soc. 1916, 38, 1503-10.

44. Bianchi, A.; Calabi, L.; Corana, F.; Fontana, S.; Losi, P.; Maiocchi, A.; Paleari, L.; Valtancoli, B., Coord. Chem. Rev. 2000, 204, 309-393.

45. Gaussian 03, Revision C.02, Frisch, M. J.; Trucks, G. W.; Schlegel, H. B.; Scuseria, G. E.; Robb, M. A.; Cheeseman, J. R.; Montgomery, Jr., J. A.; Vreven, T.; Kudin, K. N.; Burant, J. C.; Millam, J. M.; Iyengar, S. S.; Tomasi, J.; Barone, V.; Mennucci, B.; Cossi, M.; Scalmani, G.; Rega, N.; Petersson, G. A.; Nakatsuji, H.; Hada, M.; Ehara, M.; Toyota, K.; Fukuda, R.; Hasegawa, J.; Ishida, M.; Nakajima, T.; Honda, Y.; Kitao, O.; Nakai, H.; Klene, M.; Li, X.; Knox, J. E.; Hratchian, H. P.; Cross, J. B.; Bakken, V.; Adamo, C.; Jaramillo, J.; Gomperts, R.; Stratmann, R. E.; Yazyev, O.; Austin, A. J.; Cammi, R.; Pomelli, C.; Ochterski, J. W.; Ayala, P. Y.; Morokuma, K.; Voth, G. A.; Salvador, P.; Dannenberg, J. J.; Zakrzewski, V. G.; Dapprich, S.; Daniels, A. D.; Strain, M. C.; Farkas, O.; Malick, D. K.; Rabuck, A. D.; Raghavachari, K.; Foresman, J. B.; Ortiz, J. V.; Cui, Q.; Baboul, A. G.; Clifford, S.; Cioslowski, J.; Stefanov, B. B.; Liu, G.; Liashenko, A.; Piskorz, P.; Komaromi, I.; Martin, R. L.; Fox, D. J.; Keith, T.; AlLaham, M. A.; Peng, C. Y.; Nanayakkara, A.; Challacombe, M.; Gill, P. M. W.; Johnson, B.; Chen, W.; Wong, M. W.; Gonzalez, C.; and Pople, J. A.; Gaussian, Inc., Wallingford CT, 2004.

46. Gutierrez, F.; Tedeschi, C.; Maron, L.; Daudey, J.-P.; Azema, J.; Tisnes, P.; Picard, C.; Poteau, R., Theochem 2005, 756, 151-162.

47. Dreuw, A.; Head-Gordon, M., J. Amer. Chem. Soc. 2004, 126, 4007-4016.

48. Werts, M. H. V.; Jukes, R. T. F.; Verhoeven, J. W., Phys. Chem. Chem. Phys., 2002, 4, 15421548.

49. Supkowski, R. M.; Horrocks, W. D., Jr., Inorg. Chim. Acta 2002, 340, 44-48.

50. Muller, G.; Schmidt, B.; Jiricek, J.; Hopfgartner, G.; Riehl, J. P.; Bünzli, J.-C. G.; Piguet, C., J. Chem. Soc., Dalton Trans., 2001, 2655-2662.

51. Lanthanide Probes in Life, Chemical and Earth Sciences: Theory and Practice. Bünzli, J-C. G. Choppin, G. R.: 1989.

52. Latva, M.; Takalo, H.; Mukkala, V.-M.; Matachescu, C.; Rodriguez-Ubis, J. C.; Kankare, J., J. Lumin., 1997, 75, 149-169.

53. Arnaud, N.; Georges, J., Spectrochim Acta A, Mol Biomol. Spectrosc., 2003, 59, 1829-40. 
Chart 1. Tetradentate 1,2-HOPO based ligands for sensitization of Eu(III) and Sm(III).

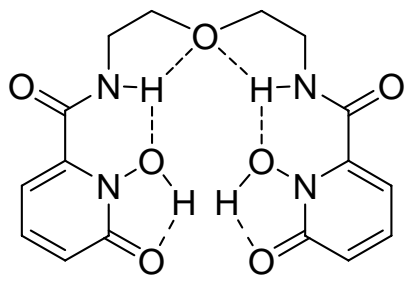

5LIO-1,2-HOPO $\left(\mathrm{H}_{2} \mathbf{1}\right)$

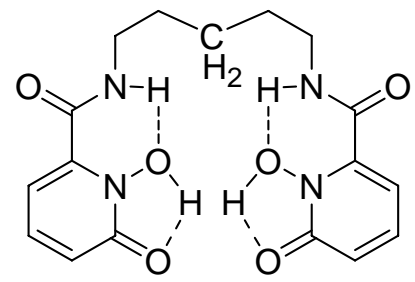

5LI-1,2-HOPO $\left(\mathrm{H}_{2} 2\right)$

Chart 2. Structural analogues of the ligand scaffolds for the 1,2-HOPO ligands.<smiles>O=C(O)CN(CCOCCN(CC(=O)O)CC(=O)O)CC(=O)O</smiles>

EEDTA<smiles>O=C(O)CN(CCCCCCN(CC(=O)O)CC(=O)O)CC(=O)O</smiles> 

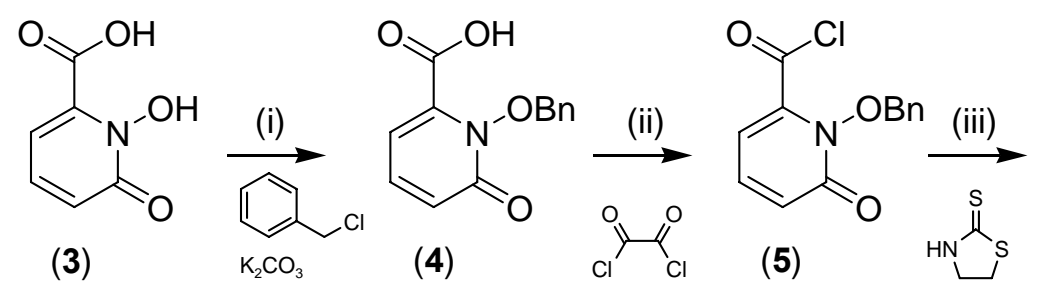<smiles>O=C(c1cccc(=O)n1OCc1ccccc1)N1CCSC1=S</smiles><smiles>[X]CCCNC(=O)c1cccc(=O)n1O</smiles><smiles>CC(=O)OCC(C)C</smiles><smiles></smiles><smiles>CCCCCCCCC(=O)OC</smiles>

$\left(\mathrm{H}_{2}\right.$ 1) 5LIO-1,2-HOPO, $\mathrm{X}=\mathrm{O}$

(7) $5 \mathrm{LIO}-1,2-\mathrm{HOPO}-\mathrm{Bn}, \mathrm{X}=\mathrm{O}$

$\left(\mathrm{H}_{2} 2\right) 5 \mathrm{LI}-1,2-\mathrm{HOPO}, \mathrm{X}=\mathrm{CH}_{2}$

(8) $5 \mathrm{LI}-1,2-\mathrm{HOPO}-\mathrm{Bn}, \mathrm{X}=\mathrm{CH}_{2}$

Scheme 1. Synthesis of 5LIO-1,2-HOPO $\left(\mathrm{H}_{2} \mathbf{1}\right)$ and 5LI-1,2-HOPO $\left(\mathrm{H}_{2} 2\right)$ via the readily accessible 1,2-HOPO-Bn-thiaz (6). 

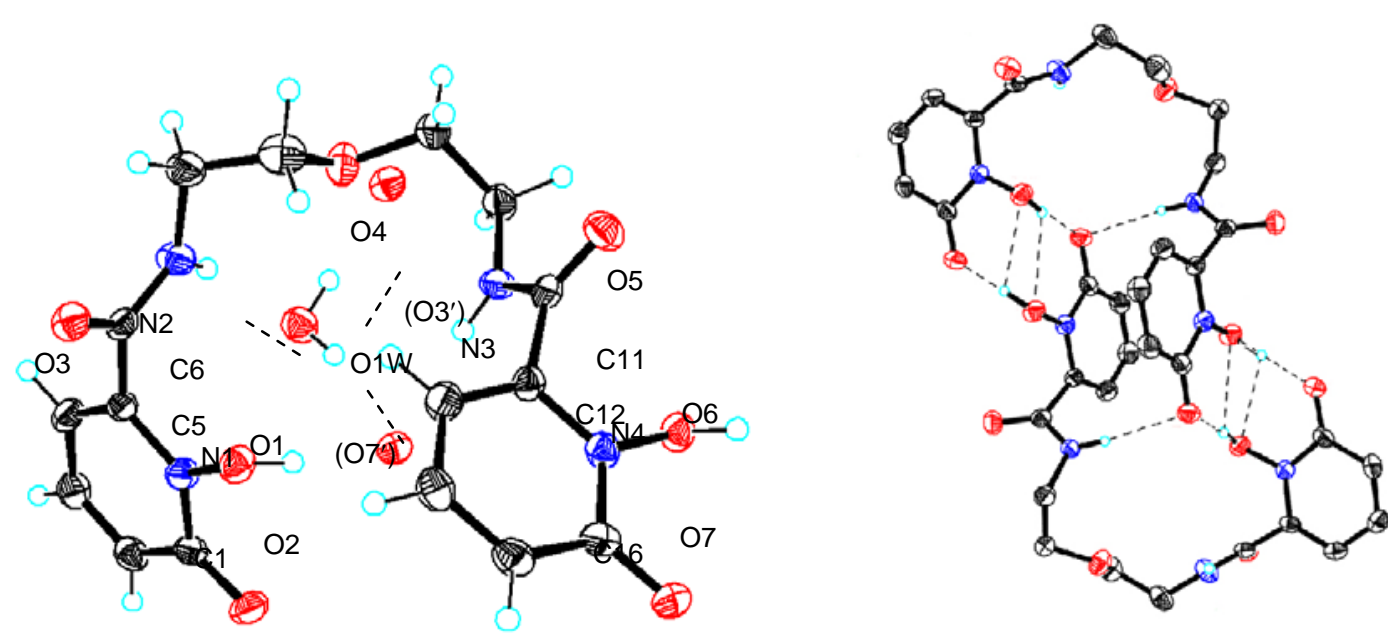

Figure 1. Two views of the crystal structure of $\left(\mathrm{H}_{2} \mathbf{1}\right)$ that illustrate the intermolecular hydrogen bonding network (dashed lines - atoms labeled in parenthesis are symmetry related) and $\pi$ stacking interactions which link each molecule into dimers in the unit cell packing. Selected $\mathrm{H}$ atoms have been omitted for clarity and non-H atoms are drawn at the $50 \%$ probability level. 

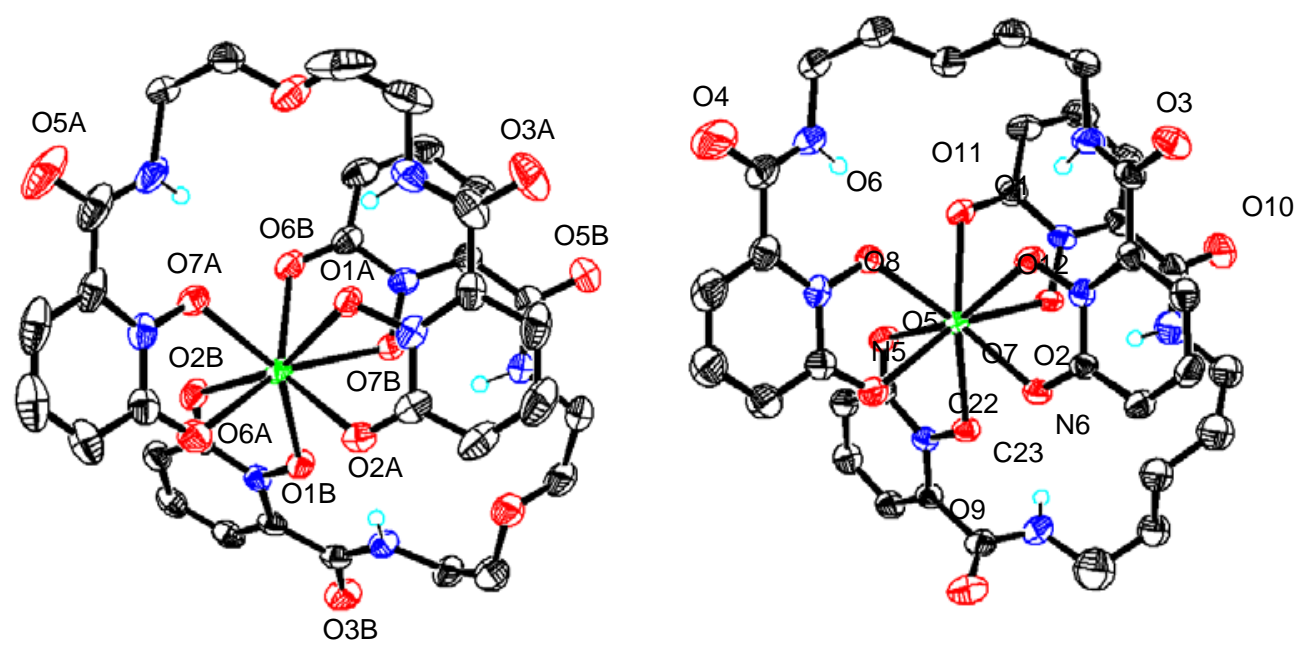

Figure 2. A comparison of reported ${ }^{18}$ crystal structures for $\mathrm{C}_{4} \mathrm{H}_{12} \mathrm{~N}^{+}\left[\mathrm{Eu}(\mathbf{1})_{2}\right]^{-}$(left) with observed structure of $\mathrm{C}_{2} \mathrm{H}_{8} \mathrm{~N}^{+}\left[\mathrm{Eu}(2)_{2}\right]^{-} \cdot\left(\mathrm{C}_{3} \mathrm{H}_{7} \mathrm{NO}\right)_{2}$ (right). Only the major components of disordered ligand backbones are shown. The counter cations, co-crystallized solvent molecules, and selected $\mathrm{H}$ atoms have been omitted for clarity and non-H atoms are drawn at the $50 \%$ probability level. 

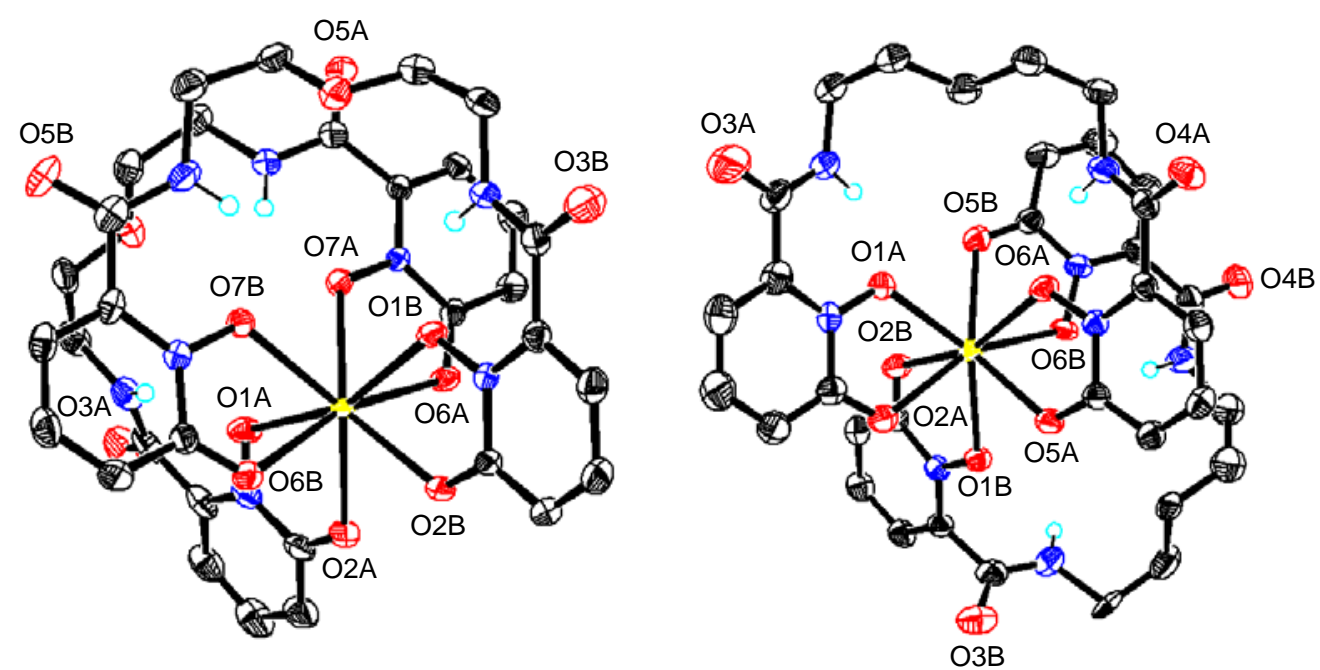

Figure 3. A comparison of observed structures for the $\mathrm{C}_{4} \mathrm{H}_{12} \mathrm{~N}^{+}\left[\operatorname{Sm}(\mathbf{1})_{2}\right]^{-} \cdot \mathrm{CH}_{3} \mathrm{OH} \cdot \mathrm{H}_{2} \mathrm{O}$ (left) and $\mathrm{C}_{2} \mathrm{H}_{8} \mathrm{~N}^{+}\left[\mathrm{Sm}(2)_{2}\right]^{-} \cdot\left(\mathrm{C}_{3} \mathrm{H}_{7} \mathrm{NO}\right)_{1.5}$ (right) complexes. Only the major components of disordered ligand backbones are shown. The counter cations, co-crystallized solvent molecules, and selected $\mathrm{H}$ atoms have been omitted for clarity and non-H atoms are drawn at the $50 \%$ probability level. 


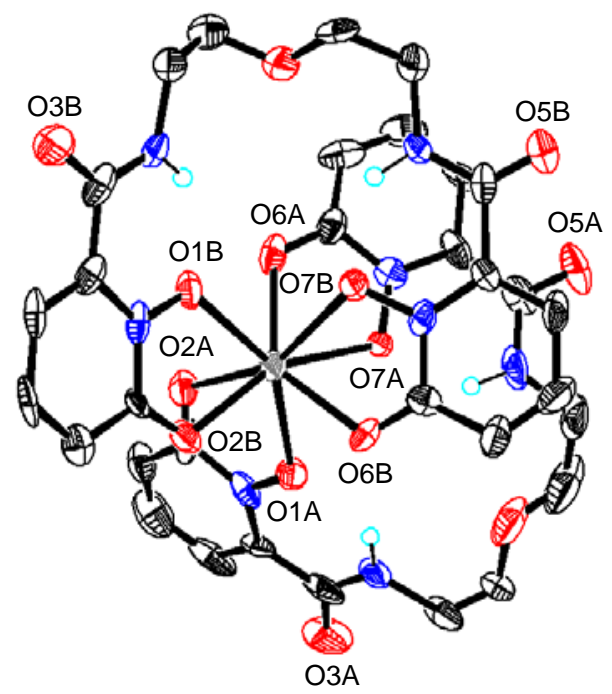

Figure 4. The $\mathrm{C}_{4} \mathrm{H}_{12} \mathrm{~N}^{+}\left[\mathrm{Gd}(\mathbf{1})_{2}\right]^{-}$complex structure. The tetramethylammonium counter cation and selected $\mathrm{H}$ atoms have been omitted for clarity and non- $\mathrm{H}$ atoms are drawn at the $50 \%$ probability level. 

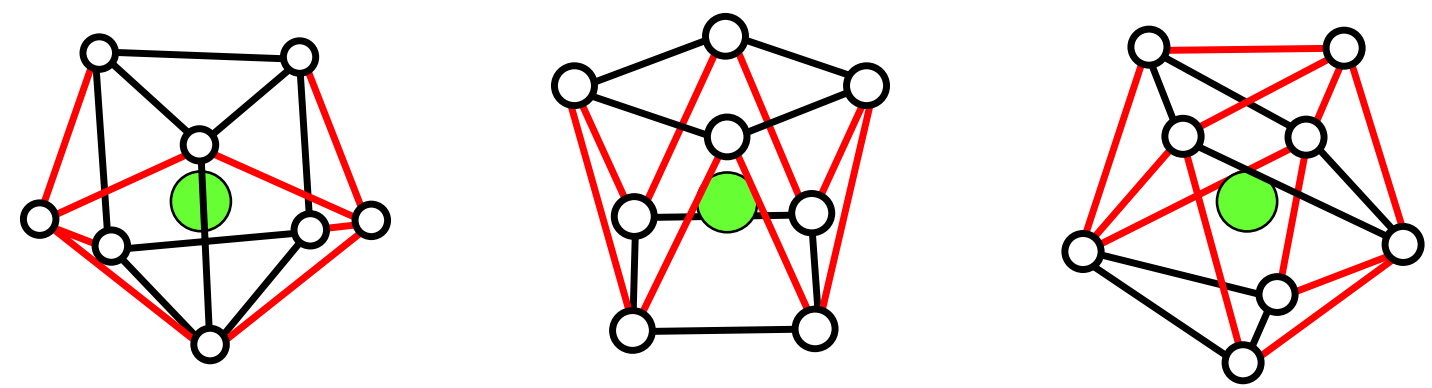

Figure 5. The three differing ideal coordination polyhedra of donor atoms (white spheres) for an eight coordinate $\mathrm{Ln}(\mathrm{III})$ metal centre (green) are, from left to right, the bicapped trigonal prism $\left(\mathrm{C}_{2 v}\right)$, the square antiprism $\left(\mathrm{D}_{4 d}\right)$ and the trigonal dodecahedron $\left(\mathrm{D}_{2 d}\right)$. 


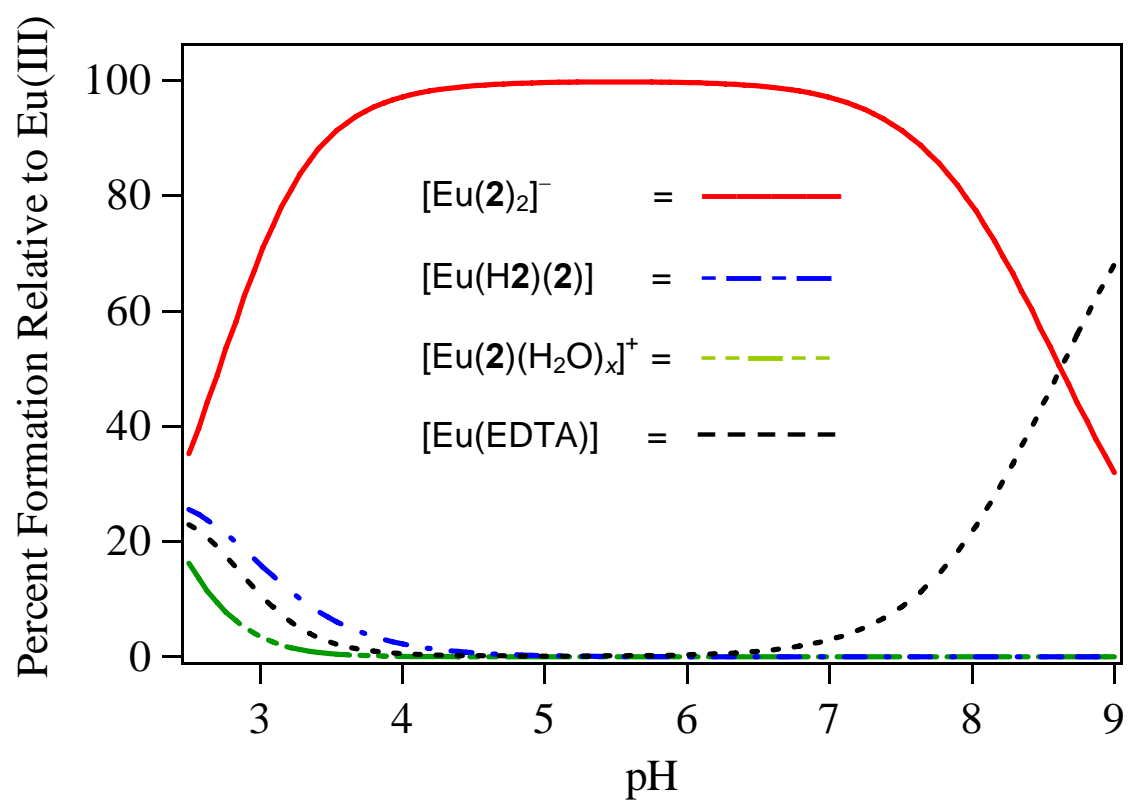

Figure 6. Speciation diagram for $\left[\mathrm{Eu}(2)_{2}\right]^{-}$under $\mathrm{pM}$ conditions $(1 \mu \mathrm{M} \mathrm{Eu}(\mathrm{III}), 10 \mu \mathrm{M}$ ligand $)$ in the presence of 1000 fold excess of EDTA. 


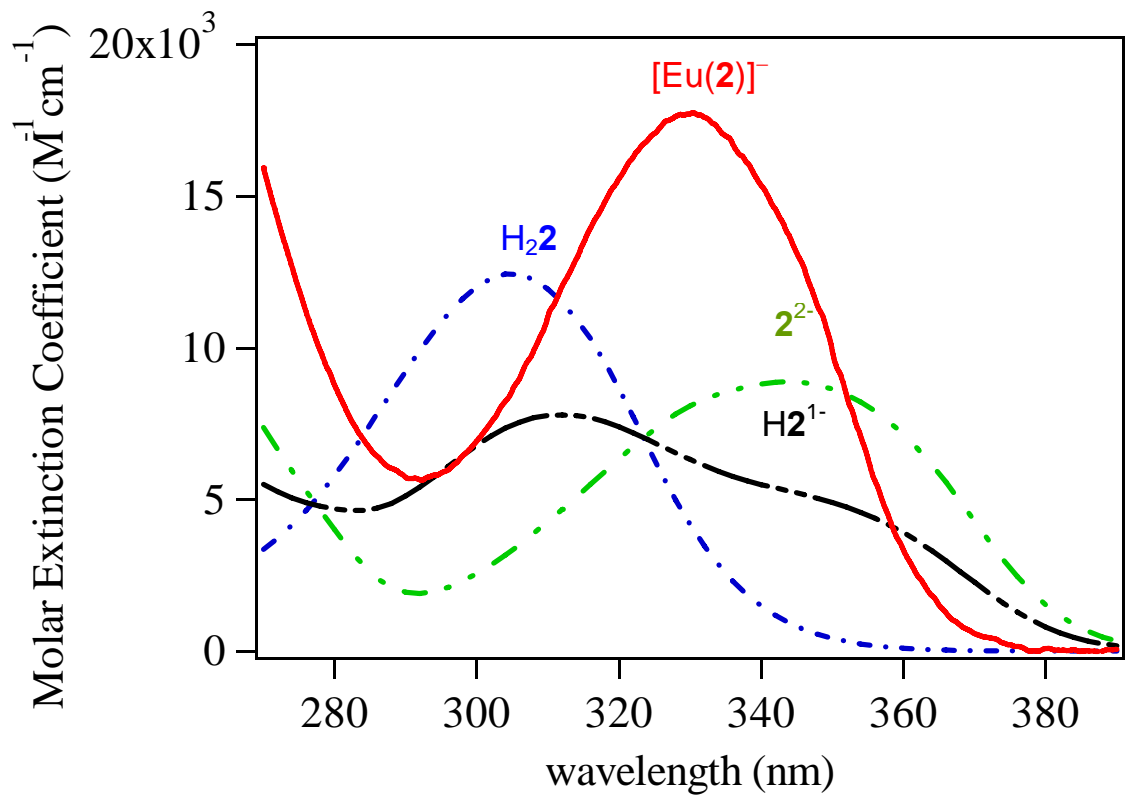

Figure 7. Absorption spectra for the 5LI-1,2-HOPO ligand, $\mathrm{H}_{2} \mathbf{2}(-\cdot--)$, its monoanion $\mathrm{H}^{1-}(-\cdot--)$ and dianion $\mathbf{2}^{2-}(-\cdot \cdot)$ and the corresponding spectra observed for the $\left(\left[\operatorname{Eu}(\mathbf{2})_{2}\right]^{-}=-\right)$complex in $0.1 \mathrm{M}$ TRIS buffer at $\mathrm{pH}$ 7.4. 


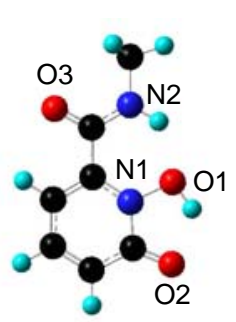

Output geometry

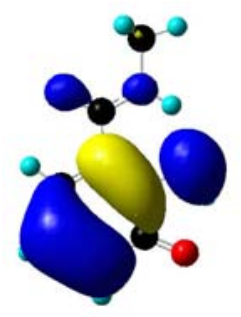

HOMO-4

$(n=40)$

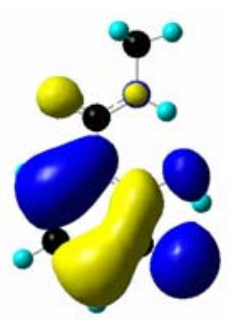

HOMO

$(n=44)$

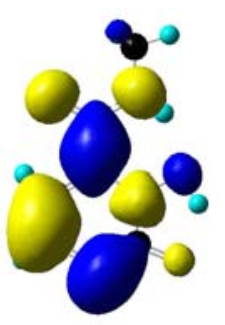

LUMO

$(n=45)$

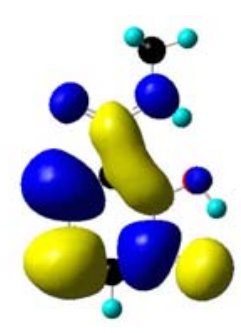

LUMO+1

$(n=46)$

Figure 8. Calculated output geometry obtained from static B3LYP/6-311G++ (d,p) geometry optimization and corresponding molecular orbital diagrams from TD-DFT electronic structure calculations for a model 6-MeAmide-1,2-HOPO chromophore. 

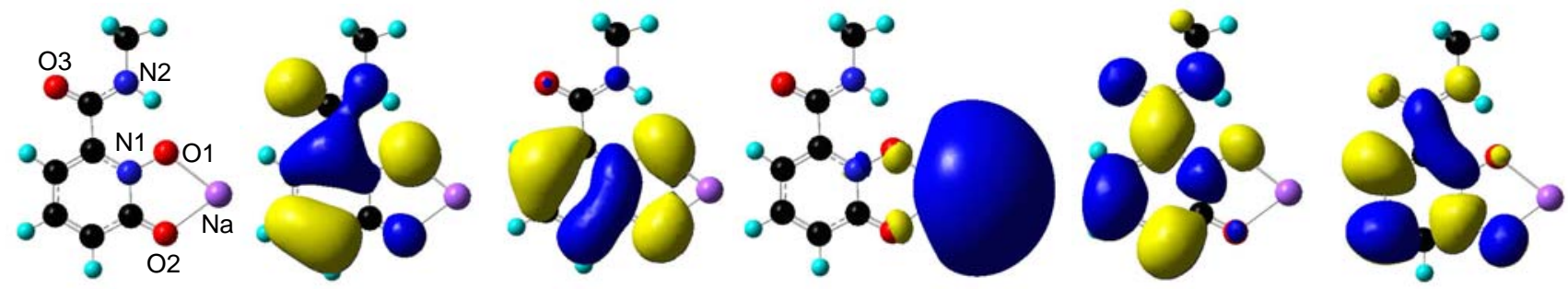

$$
\begin{array}{cc}
\text { Output } & \text { HOMO-1 } \\
\text { geometry } & (n=48)
\end{array}
$$

\section{HOMO}

LUMO

$(n=50)$
$\mathrm{LUMO}+1$
$(n=51)$
LUMO+5
$(n=55)$

Figure 9. Calculated output geometry obtained from static B3LYP/6-311G++ (d,p) geometry optimization and corresponding molecular orbital diagrams from TD-DFT electronic structure calculations for a model $[\mathrm{Na}(6-\mathrm{Me} A$ mide-1,2-HOPO)] complex. The metal centered character of the LUMO is an artifact of the B3LYP functional calculation (see text). 


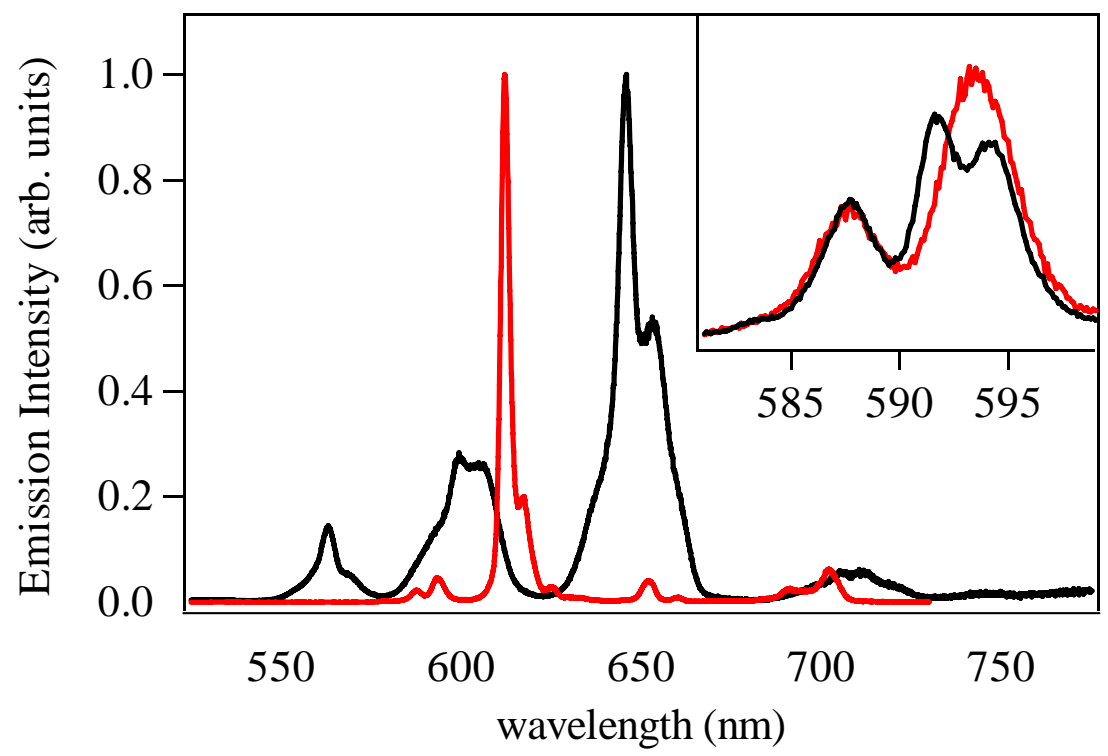

Figure 10. Normalized emission spectra $\left(\lambda_{\mathrm{ex}}=330 \mathrm{~nm}\right)$ for $1 \times 10^{-6} \mathrm{M}$ solutions of the $\mathrm{Eu}(\mathrm{III})$ (red) and Sm(III) (black) $\mathrm{ML}_{2}$ complexes of (2) in $0.1 \mathrm{M}$ TRIS buffer at $\mathrm{pH} 7.4\left(\lambda_{\mathrm{ex}}=330 \mathrm{~nm}\right)$. Inset: A comparison of solid state (black) and solution (red) emission spectra for the $\left[\mathrm{Eu}(2)_{2}\right]^{-}$complex in the ${ }^{5} \mathrm{D}_{0} \rightarrow{ }^{7} \mathrm{~F}_{1}$ spectral region. 


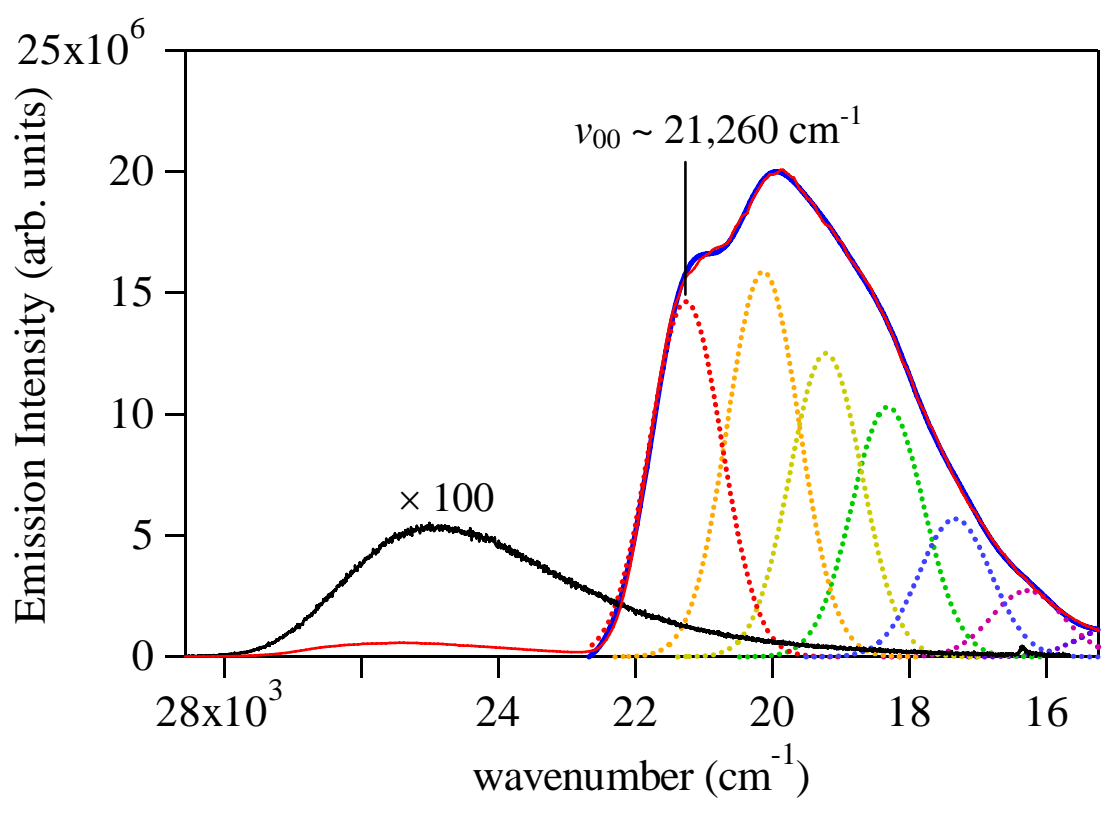

Figure 11. Comparison of room temperature $(\times 100$, black $)$ and $77 \mathrm{~K}$ (red) emission spectra of the $[\mathrm{Gd}(\mathbf{1})]^{-}$complex, with spectral deconvolution (blue) of the latter into a vibronic progression of several overlapping Gaussian functions with separations of $c a \cdot 1000-1100 \mathrm{~cm}^{-1}$ to determine $v_{00}$ of the $\mathrm{T}_{0}$ energy. 
Table 1. Summary of crystal data obtained for 5LIO-1,2-HOPO $\left(\mathrm{H}_{2} \mathbf{1}\right)$ and 5LI-1,2-HOPO $\left(\mathrm{H}_{2} 2\right)$ with several Ln(III) complexes.

\begin{tabular}{|c|c|c|c|c|c|c|}
\hline & $\mathbf{H}_{2} \mathbf{1} \cdot \mathbf{H}_{2} \mathrm{O}$ & $\mathrm{C}_{4} \mathrm{H}_{12} \mathrm{~N}\left[\mathrm{Eu}(1)_{2}\right]$ & $\begin{array}{c}\mathrm{C}_{4} \mathrm{H}_{12} \mathrm{~N}\left[\mathrm{Sm}(1)_{2}\right] \cdot \mathrm{CH}_{3} \mathrm{OH} \cdot \\
\mathrm{H}_{2} \mathrm{O}\end{array}$ & $\mathrm{C}_{4} \mathrm{H}_{12} \mathrm{~N}\left[\mathrm{Gd}(1)_{2}\right]$ & $\begin{array}{c}\mathrm{C}_{2} \mathrm{H}_{8} \mathrm{~N}\left[\mathrm{Eu}(2)_{2}\right] \\
\cdot\left(\mathrm{C}_{3} \mathrm{H}_{7} \mathrm{NO}\right)_{2} \\
\end{array}$ & $\begin{array}{c}\mathrm{C}_{2} \mathrm{H}_{8} \mathrm{~N}\left[\mathrm{Sm}(2)_{2}\right] \\
\cdot\left(\mathrm{C}_{3} \mathrm{H}_{7} \mathrm{NO}\right)_{1.5} \\
\end{array}$ \\
\hline empirical formula & $\mathrm{C}_{16} \mathrm{H}_{20} \mathrm{~N}_{4} \mathrm{O}_{8}$ & $\mathrm{C}_{36} \mathrm{H}_{44} \mathrm{~N}_{9} \mathrm{O}_{14} \mathrm{Eu}$ & $\mathrm{C}_{37} \mathrm{H}_{50} \mathrm{~N}_{9} \mathrm{O}_{16} \mathrm{Sm}$ & $\mathrm{C}_{36} \mathrm{H}_{44} \mathrm{~N}_{9} \mathrm{O}_{4} \mathrm{Gd}$ & $\mathrm{C}_{42} \mathrm{H}_{57} \mathrm{~N}_{11} \mathrm{O}_{14} \mathrm{Eu}$ & $\mathrm{C}_{40.5} \mathrm{H}_{54.5} \mathrm{~N}_{10.5} \mathrm{O}_{13.5} \mathrm{Sm}$ \\
\hline mol. wt. [g.mol ${ }^{-1}$ ] & 396.36 & 978.76 & 1027.21 & 984.05 & 1091.95 & 1054.8 \\
\hline crystal system & monoclinic & monoclinic & monoclinic & monoclinic & monoclinic & monoclinic \\
\hline space group & $\mathrm{P} 2_{1} / \mathrm{n}$ & $\mathrm{P} 2_{1} / \mathrm{n}$ & $\mathrm{P} 2_{1} / \mathrm{c}$ & $\mathrm{P} 2{ }_{1} / \mathrm{c}$ & $\mathrm{P} 2_{1} / \mathrm{n}$ & $\mathrm{P} 2{ }_{1} / \mathrm{n}$ \\
\hline$a[\AA]$ & $15.272(13)$ & $10.0579(16)$ & $8.6048(5)$ & $10.028(5)$ & $17.3141(19)$ & $17.3156(18)$ \\
\hline$b[\AA]$ & $6.836(6)$ & $17.848(3)$ & $18.4988(11)$ & $17.771(5)$ & $13.1648(14)$ & $13.1786(14)$ \\
\hline$c[\AA]$ & $17.852(15)$ & $22.642(4)$ & $26.6387(16)$ & $22.564(5)$ & $22.461(2)$ & $22.469(2)$ \\
\hline$\alpha$ [deg.] & 90 & 90 & 90 & 90 & 90 & 90 \\
\hline$\beta$ [deg.] & $108.307(11)$ & $92.781(2)$ & $90.6180(5)$ & $111.087(19)$ & $112.104(1)$ & $112.105(1)$ \\
\hline$\gamma$ [deg.] & 90 & 90 & 90 & 90 & 90 & 90 \\
\hline volume $\left[\AA^{3}\right]$ & $1769(3)$ & $4059.8(12)$ & $4240.1(4)$ & $3752.0(2)$ & $4743.4(9)$ & $4750.4(9)$ \\
\hline$Z$ & 4 & 4 & 4 & 4 & 4 & 4 \\
\hline density, $\rho\left[\mathrm{g} \mathrm{cm}^{-3}\right]$ & 1.488 & 1.601 & 1.609 & 1.742 & 1.529 & 1.475 \\
\hline absorption coefficient, $\mu\left[\mathrm{mm}^{-1}\right]$ & 0.121 & 1.623 & 1.467 & 1.852 & 1.399 & 1.309 \\
\hline$F(000)$ & 832 & 1992 & 2100 & 1996 & 2244 & 2146 \\
\hline crystal size $\left[\mathrm{mm}^{3}\right]$ & $0.18 \times 0.14 \times 0.03$ & $0.40 \times 0.20 \times 0.07$ & $0.30 \times 0.20 \times 0.02$ & $0.18 \times 0.14 \times 0.02$ & $0.18 \times 0.12 \times 0.12$ & $0.15 \times 0.14 \times 0.09$ \\
\hline temperature [C] & $-145(2)$ & $-138(2)$ & $-155(2)$ & $-145(2)$ & $-145(2)$ & $-149(2)$ \\
\hline Wavelength & 0.71073 & 0.71073 & 0.71073 & 0.71073 & 0.71073 & 0.71073 \\
\hline Orange for data collection [deg] & 3.29 to 24.71 & 3.46 to 26.40 & 2.30 to 26.39 & 4.08 to 23.26 & 3.25 to 26.36 & 3.42 to 25.35 \\
\hline limiting indices & $\begin{array}{c}-17<\mathrm{h}<15,-8<\mathrm{k}<6, \\
-20<\mathrm{l}<20\end{array}$ & $\begin{array}{c}-12<\mathrm{h}<12,-22<\mathrm{k}<12 \\
-27<\mathrm{l}<27\end{array}$ & $\begin{array}{c}10<\mathrm{h}<10,-21<\mathrm{k}<21 \\
-33<\mathrm{l}<30\end{array}$ & $\begin{array}{c}-11<\mathrm{h}<11,-19<\mathrm{k}<16 \\
-25<\mathrm{l}<19\end{array}$ & $\begin{array}{c}-21<\mathrm{h}<15,-16<\mathrm{k}<14 \\
-27<\mathrm{l}<27\end{array}$ & $\begin{array}{c}-17<\mathrm{h}<20,-15<\mathrm{k}<15 \\
-27<\mathrm{l}<17\end{array}$ \\
\hline measured reflections & 7387 & 19141 & 23946 & 14912 & 22425 & 20540 \\
\hline independent reflections & $2962\left(\mathrm{R}_{\mathrm{int}}=0.0372\right)$ & $7783\left(\mathrm{R}_{\mathrm{int}}=0.0208\right)$ & $8544\left(\mathrm{R}_{\mathrm{int}}=0.0339\right)$ & $5335\left(\mathrm{R}_{\mathrm{int}}=0.0908\right)$ & $9029\left(\mathrm{R}_{\mathrm{int}}=0.0199\right)$ & $8466\left(\mathrm{R}_{\mathrm{int}}=0.0265\right)$ \\
\hline completeness to $\theta$ & 98.6 & 93.3 & 98.4 & 99.0 & 93.1 & 97.5 \\
\hline refinement method & $\begin{array}{l}\text { full-matrix least-squares } \\
\text { on } \mathrm{F}^{2}\end{array}$ & $\begin{array}{l}\text { full-matrix least-squares } \\
\text { on } \mathrm{F}^{2}\end{array}$ & $\begin{array}{l}\text { full-matrix least-squares } \\
\text { on } \mathrm{F}^{2}\end{array}$ & $\begin{array}{l}\text { full-matrix least-squares } \\
\text { on } \mathrm{F}^{2}\end{array}$ & $\begin{array}{l}\text { full-matrix least-squares } \\
\text { on } \mathrm{F}^{2}\end{array}$ & $\begin{array}{l}\text { full-matrix least-squares } \\
\text { on } \mathrm{F}^{2}\end{array}$ \\
\hline data / restraints / parameters & $2962 / 0 / 265$ & $7783 / 4 / 565$ & $8544 / 0 / 577$ & $5335 / 0 / 541$ & $9029 / 0 / 611$ & 8466 / 0 / 645 \\
\hline goodness-of-fit on $F^{2}$ & 1.000 & 1.137 & 1.0036 & 1.149 & 1.023 & 1.055 \\
\hline final $R$ indices $[I>2 \rho(I)]$ & $\begin{array}{c}\mathrm{R}_{1}=0.0314, \mathrm{wR}_{2}= \\
0.0497\end{array}$ & $\begin{array}{c}\mathrm{R}_{1}=0.0366, \mathrm{wR}_{2}= \\
0.0843\end{array}$ & $\begin{array}{c}\mathrm{R}_{1}=0.0342, \mathrm{w} \mathrm{R}_{2}= \\
0.0710\end{array}$ & $\begin{array}{c}\mathrm{R}_{1}=0.0776, \mathrm{w} \mathrm{R}_{2}= \\
0.1715\end{array}$ & $\begin{array}{c}\mathrm{R}_{1}=0.0322, \mathrm{wR}_{2}= \\
0.0773\end{array}$ & $\begin{array}{c}\mathrm{R}_{1}=0.0359, \mathrm{wR}_{2}= \\
0.0916\end{array}$ \\
\hline$R$ indices (all data) & $\begin{array}{c}\mathrm{R}_{1}=0.0575, \mathrm{wR}_{2}= \\
0.0518\end{array}$ & $\begin{array}{c}\mathrm{R}_{1}=0.0437, \mathrm{wR}_{2}= \\
0.0867\end{array}$ & $\begin{array}{c}\mathrm{R}_{1}=0.0502, \mathrm{wR}_{2}= \\
0.0752\end{array}$ & $\begin{array}{c}\mathrm{R}_{1}=0.1396, \mathrm{wR}_{2}= \\
0.1899\end{array}$ & $\begin{array}{c}\mathrm{R}_{1}=0.0458, \mathrm{wR}_{2}= \\
0.0832\end{array}$ & $\begin{array}{c}\mathrm{R}_{1}=0.0489, \mathrm{wR}_{2}= \\
0.0968\end{array}$ \\
\hline largest diff. peak and hole $\left[\mathrm{e}^{-3}\right]$ & 0.165 and -0.185 & 0.985 and -0.542 & 0.739 and -0.713 & 2.101 and -0.771 & 0.929 and -0.586 & 1.116 and -0.531 \\
\hline
\end{tabular}

a) Data taken from Ref. 18.

Table 2. Table of selected bond lengths for $\mathrm{Ln}(\mathrm{III})$ complexes of 5LIO-1,2-HOPO $\left(\mathrm{H}_{2} \mathbf{1}\right)$ and 5LI-1,2-HOPO $\left(\mathrm{H}_{2} 2\right)$.

\begin{tabular}{|c|c|c|c|c|c|c|}
\hline$\left[\mathrm{Eu}(\mathbf{1})_{2}\right]^{-}$ & Eu-O1 (hydroxyl) & 2.457 & Eu-O2 (keto) & 2.385 & O1A-H2AB (Amide) & 1.926 \\
\hline & Eu-O7A(hydroxyl) & 2.371 & Eu-O6A (keto) & 2.394 & O1B-H2B1 (Amide) & 1.917 \\
\hline & Eu-O1B (hydroxyl) & 2.372 & Eu-O2B (keto) & 2.383 & O7A-H3AA (Amide) & 1.934 \\
\hline & Eu-O7B (hydroxyl) & 2.434 & Eu-O6B (keto) & 2.380 & O7B-H3BA (Amide) & 1.938 \\
\hline \multirow[t]{4}{*}[\mathrm{Eu}(\mathbf{2})_{2}]{$^{-}$} & Eu-O1 (hydroxyl) & 2.400 & Eu-O2 (keto) & 2.387 & O1-H4 (amide) & 1.893 \\
\hline & Eu-O6 (hydroxyl) & 2.373 & Eu-O5 (keto) & 2.413 & O7-H22 (amide) & 3.189 \\
\hline & Eu-O7 (hydroxyl) & 2.422 & Eu-O8 (keto) & 2.382 & O6-H15 (amide) & 1.882 \\
\hline & Eu-O12 (hydroxyl) & 2.375 & Eu-O11 (keto) & 2.380 & O12-H41 (amide) & 1.926 \\
\hline
\end{tabular}




\begin{tabular}{|c|c|c|c|c|c|c|}
\hline$\overline{\left[\mathrm{Sm}(\mathbf{1})_{2}\right]^{-}}$ & Sm-O1A (hydroxyl) & 2.429 & Sm-O2A (keto) & 2.423 & O1-H104 (amide) & 1.982 \\
\hline & Sm-O7A (hydroxyl) & 2.368 & Sm-O6A (keto) & 2.427 & O1B-H204 & 1.917 \\
\hline & Sm-O1B (hydroxyl) & 2.435 & Sm-O2B (keto) & 2.381 & O7A-H113 (amide) & 1.904 \\
\hline & Sm-O7B (hydroxyl) & 2.394 & Sm-O6B (keto) & 2.421 & O7B-H213 & 2.011 \\
\hline \multirow{4}{*}[\mathrm{Sm}(\mathbf{2})_{2}]{$^{-}$} & Sm-O1A (hydroxyl) & 2.387 & Sm-O2A (keto) & 2.427 & O1A-H104 (amide) & 1.874 \\
\hline & Sm-O6A (hydroxyl) & 2.405 & Sm-O5A (keto) & 2.398 & O1B-H204 (amide) & 3.253 \\
\hline & Sm-O1B (hydroxyl) & 2.432 & Sm-O2B (keto) & 2.398 & O6A-H115 (amide) & 1.895 \\
\hline & Sm-O6B (hydroxyl) & 2.383 & Sm-O5B (keto) & 2.396 & O6B-H223 (amide) & 1.926 \\
\hline \multirow[t]{4}{*}[\mathrm{Gd}(\mathbf{1})_{2}]{$^{-}$} & Gd-O1A (hydroxyl) & 2.343 & Gd-O2A (keto) & 2.268 & O1A-H4 (amide) & 1.896 \\
\hline & Gd-O7A (hydroxyl) & 2.332 & Gd-O6A (keto) & 2.331 & O1B-H2 (amide) & 1.961 \\
\hline & Gd-O1B (hydroxyl) & 2.328 & Gd-O2B (keto) & 2.295 & O7A-H5 (amide) & 1.825 \\
\hline & Gd-O7B (hydroxyl) & 2.327 & Gd-O6B (keto) & 2.318 & O7B-H3 (amide) & 1.875 \\
\hline
\end{tabular}


Table 3. Shape measure analyses of $\mathrm{Ln}(\mathrm{III})$ complexes with 5LIO-1,2-HOPO $\left(\mathrm{H}_{2} \mathbf{1}\right)$ and 5LI-1,2-HOPO $\left(\mathrm{H}_{2} 2\right)$.

\begin{tabular}{|c|c|c|c|}
\hline $\begin{array}{c}\text { Comple } \\
\mathbf{x}\end{array}$ & $\begin{array}{c}\text { square antiprism } \\
\left(\mathbf{D}_{4 d}\right)\end{array}$ & $\begin{array}{c}\text { bicapped trigonal } \\
\text { prism }\left(\mathbf{C}_{2 v}\right)\end{array}$ & $\begin{array}{c}\text { trigonal } \\
\text { dodecahedron }\left(\mathbf{D}_{2 d}\right)\end{array}$ \\
\hline$\left[\mathrm{Eu}(\mathbf{1})_{2}\right]^{-}$ & 19.21 & 17.24 & 20.37 \\
\hline$\left[\mathrm{Eu}(\mathbf{2})_{2}\right]^{-}$ & 17.79 & 11.53 & 14.06 \\
\hline$\left[\mathrm{Sm}(\mathbf{1})_{2}\right]^{-}$ & 28.43 & 27.82 & 24.73 \\
\hline$\left[\mathrm{Sm}(\mathbf{2})_{2}\right]^{-}$ & 17.83 & 11.48 & 14.22 \\
\hline$\left[\mathrm{Gd}(\mathbf{1})_{2}\right]^{-}$ & 18.24 & 13.60 & 19.06 \\
\hline
\end{tabular}

Table 4. Summary of $\mathrm{pK}_{\mathrm{a}}$ values and $\mathrm{Eu}(\mathrm{III})$ binding constants for tetradentate 1,2-HOPO ligands.

\begin{tabular}{|c|c|c|}
\hline & 5LIO-1,2-HOPO* $\left(\mathrm{H}_{2} 1\right)$ & 5LI-1,2-HOPO $\left(\mathrm{H}_{2} 2\right)$ \\
\hline $\mathbf{p K}_{\mathrm{a} 1}$ & $4.19(3)$ & $4.52(3)$ \\
\hline $\mathbf{p K _ { \mathrm { a } 2 }}$ & $5.79(1)$ & $5.65(1)$ \\
\hline$\Sigma \mathbf{p K}_{\mathbf{a}}$ & 9.98 & 10.17 \\
\hline$p K_{\mathrm{a} 2}-\mathbf{p K _ { \mathrm { a } 1 }}$ & 1.60 & 1.13 \\
\hline $\log _{10} \beta_{110}$ & $12.46(2)$ & $12.33(1)$ \\
\hline $\log _{10} \beta_{120}$ & $22.85(10)$ & $22.56(5)$ \\
\hline $\log _{10} \beta_{121}$ & $25.21(3)$ & $25.40(1)$ \\
\hline $\mathbf{p E u ^ { \dagger }}$ & $18.64(10)$ & $18.35(5)$ \\
\hline
\end{tabular}

$\dagger$ At $\mathrm{pH}=7.4,[\mathrm{~L}]=10^{-5} \mathrm{M},[\mathrm{Eu}]=10^{-6} \mathrm{M} . *$ Data taken from Ref. 18. 
Table 5. Summary of electronic structure calculations for 1,2-HOPO chromophore and $\mathrm{Na}^{+}$complex.

\begin{tabular}{|c|c|c|c|c|c|c|c|}
\hline & $\begin{array}{c}\text { Excited } \\
\text { State }\end{array}$ & $\begin{array}{l}\text { Multiplicit } \\
\mathbf{y}\end{array}$ & $\begin{array}{l}\text { Energ } \\
\begin{array}{l}\mathrm{y} \\
(\mathrm{eV})\end{array}\end{array}$ & $\begin{array}{c}\text { Wavelengt } \\
\mathbf{h} \\
(\mathbf{n m})\end{array}$ & $\begin{array}{l}\text { Oscillator } \\
\text { Strength }\end{array}$ & $\begin{array}{c}\text { Orbital(s) } \\
\text { Involved } \\
\left(n \rightarrow n^{\prime}\right)\end{array}$ & $\begin{array}{l}\text { Transition } \\
\text { Coefficient }\end{array}$ \\
\hline \multirow{5}{*}{$\begin{array}{l}\text { 6-MeAmide-1,2- } \\
\text { HOPO }\end{array}$} & 1 & $\mathrm{~T}_{0}$ & 2.542 & 487.72 & 0.0000 & $44 \rightarrow 45$ & 0.7764 \\
\hline & 2 & $\mathrm{~T}_{1}$ & 3.529 & 351.37 & 0.0000 & $\begin{array}{l}43 \rightarrow 45 \\
43 \rightarrow 46 \\
43 \rightarrow 52\end{array}$ & $\begin{array}{c}0.7083 \\
-0.1733 \\
-0.2036 \\
\end{array}$ \\
\hline & 3 & $\mathrm{~T}_{2}$ & 3.706 & 334.55 & 0.0000 & $\begin{array}{l}41 \rightarrow 45 \\
42 \rightarrow 45 \\
42 \rightarrow 46 \\
42 \rightarrow 52\end{array}$ & $\begin{array}{c}0.1085 \\
0.6903 \\
-0.1149 \\
-0.1241 \\
\end{array}$ \\
\hline & 4 & $\mathrm{~T}_{3}$ & 3.708 & 334.38 & 0.0000 & $\begin{array}{l}40 \rightarrow 45 \\
44 \rightarrow 46 \\
44 \rightarrow 52\end{array}$ & $\begin{array}{c}0.4211 \\
0.6292 \\
-0.1300\end{array}$ \\
\hline & 5 & $\mathrm{~S}_{1}$ & 3.8185 & 324.69 & 0.1395 & $\begin{array}{l}40 \rightarrow 46 \\
44 \rightarrow 45\end{array}$ & $\begin{array}{l}-0.1235 \\
0.6385 \\
\end{array}$ \\
\hline \multirow{5}{*}{$\begin{array}{l}\text { [Na(6-MeAmide-1,2- } \\
\text { HOPO)] }\end{array}$} & 1 & $\mathrm{~T}_{0}$ & 2.649 & 468.05 & 0.0000 & $49 \rightarrow 51$ & 0.7643 \\
\hline & 2 & $\mathrm{~T}_{1}$ & 3.186 & 389.15 & 0.0000 & $49 \rightarrow 50$ & 0.7035 \\
\hline & 3 & $\mathrm{~S}_{1}$ & 3.205 & 386.85 & 0.0060 & $49 \rightarrow 50$ & 0.7039 \\
\hline & 4 & $\mathrm{~T}_{2}$ & 3.2404 & 382.62 & 0.0000 & $\begin{array}{l}47 \rightarrow 51 \\
48 \rightarrow 51 \\
49 \rightarrow 53 \\
49 \rightarrow 55\end{array}$ & $\begin{array}{c}0.2295 \\
0.6406 \\
-0.1884 \\
0.3529 \\
\end{array}$ \\
\hline & 5 & $\mathrm{~S}_{2}$ & 3.755 & 330.18 & 0.1066 & $\begin{array}{l}48 \rightarrow 55 \\
49 \rightarrow 51\end{array}$ & $\begin{array}{c}-0.1331 \\
0.6356 \\
\end{array}$ \\
\hline
\end{tabular}


Table 6. Summary of photophysical data for complexes of tetradentate 1,2-HOPO ligands.

\begin{tabular}{|c|c|c|c|c|c|c|}
\hline Complex & $\begin{array}{l}\lambda_{\max } \\
(\mathbf{n m})\end{array}$ & $\begin{array}{c}\varepsilon \\
\left(\mathbf{M}^{-1} \mathbf{c m}^{-1}\right)\end{array}$ & $\begin{array}{l}\Phi_{\text {tot }} \\
(\%)\end{array}$ & $\begin{array}{c}\tau \\
(\mu \mathrm{sec})\end{array}$ & $\begin{array}{c}k_{\mathrm{r}}\left(\mathrm{calc}^{\top} \mathrm{d}\right)^{\dagger} \\
\left(\mathrm{ms}^{-1}\right)\end{array}$ & $\begin{array}{c}k_{n r}\left(\text { calc'd }^{\dagger}\right)^{\dagger} \\
\left(\mathrm{ms}^{-1}\right)\end{array}$ \\
\hline$\left[\mathrm{Eu}(5 \mathrm{LIO}-1,2-\mathrm{HOPO})_{2}\right]^{-*}$ & 332.7 & 19,250 & 21.5 & $727(1012)^{\dagger}$ & 0.61 & 0.81 \\
\hline$\left[\mathrm{Eu}(5 \mathrm{LI}-1,2-\mathrm{HOPO})_{2}\right]^{-}$ & 331.4 & 18,800 & 20.7 & $\begin{array}{c}737 \\
(996.2)^{\dagger}\end{array}$ & 0.62 & 0.74 \\
\hline$\left[\mathrm{Sm}(5 \mathrm{LIO}-1,2-\mathrm{HOPO})_{2}\right]^{-}$ & 333.0 & 19,200 & 0.44 & 13.4 & N/A & N/A \\
\hline$\left[\mathrm{Sm}(5 \mathrm{LI}-1,2-\mathrm{HOPO})_{2}\right]^{-}$ & 331.3 & 19,400 & 0.44 & 10.7 & N/A & N/A \\
\hline
\end{tabular}

Data taken from Ref. 18. $\dagger$ Corresponding value obtained with $\mathrm{D}_{2} \mathrm{O}$ as solvent. $\ddagger$ Calculated from the ratio of the integrated area for the $J=1$ transition compared to the total integrated area as per the method described in Ref. 48.

Table 7. Analysis of crystal field splitting under various site symmetries for the most common eight co-ordinate $\mathrm{Ln}$ (III) geometries, and separation into corresponding symmetry allowed electronic transitions. ED and MD in parenthesis indicate the principal character and hence selection rules used for each transition, which are either induced electrical dipole or magnetic dipole respectively.

\begin{tabular}{|l|c|c|c|c|}
\hline $\mathbf{C N}=\mathbf{8}$ & $\begin{array}{c}\text { Site } \\
\text { Symmetry }\end{array}$ & $\begin{array}{c}\mathbf{D}_{\mathbf{5}} \mathbf{D}^{\mathbf{7}} \mathbf{F}_{\mathbf{0}} \\
(\mathbf{E D})\end{array}$ & $\begin{array}{c}{ }^{\mathbf{5}} \mathbf{D}_{\mathbf{0}} \rightarrow \mathbf{F}_{\mathbf{1}} \\
\mathbf{( M D})\end{array}$ & $\begin{array}{c}{ }^{\mathbf{5}} \mathbf{D}_{\mathbf{0}} \rightarrow{ }^{\mathbf{7}} \mathbf{F}_{\mathbf{2}} \\
(\mathbf{E D})\end{array}$ \\
\hline Bicapped Trigonal Prism & $\mathrm{C}_{2 \mathrm{v}}$ & $\mathrm{A}_{1}$ & $\mathrm{~A}_{2}, \mathrm{~B}_{1}, \mathrm{~B}_{2}$ & $2 \mathrm{~A}_{1}, \mathrm{~B}_{1}, \mathrm{~B}_{2}$ \\
\hline Square Antiprism & $\mathrm{D}_{4 \mathrm{~d}}$ & none & $\mathrm{A}_{2}, \mathrm{E}_{3}$ & $\mathrm{E}_{1}$ \\
\hline Trigonal Dodecahedron & $\mathrm{D}_{2 \mathrm{~d}}$ & none & $\mathrm{A}_{2}, \mathrm{E}$ & $\mathrm{B}_{2}, \mathrm{E}$ \\
\hline
\end{tabular}

